\title{
Dowsing for salinity tolerance related genes in chickpea through genome wide association and in silico PCR analysis
}

\author{
Shaimaa M. Ahmed ${ }^{3 \& 4}$, A.M. Alsamman ${ }^{4}$, M.H. Mubarak ${ }^{5}$, M.A. Badawy², M.A. Kord ${ }^{3}$, O.A. \\ Momtaz $^{1}$ and A. Hamwieh ${ }^{4 *}$ \\ ${ }^{1}$ Chemistry Dept., Faculty of Science, Cairo University. \\ ${ }^{2}$ Botany Department, Faculty of Science, Cairo University. \\ ${ }^{4}$ Agricultural genetic engineering research institute, PO Box12619, Giza, Egypt. \\ ${ }^{3}$ International Center for Agricultural Research in the Dry Areas (ICARDA), PO Box 2416, \\ Cairo, Egypt. \\ *a.hamwieh@cgiar.org
}

\section{Abstract}

Soil salinity is a major abiotic stress severely limits agricultural crop production throughout the world, and the stress is increasing particularly in the irrigated agricultural areas. Chickpea (Cicer arietinum L.) is an important grain legume that plays a significant role in the nutrition of the developing world. In this study, we used a chickpea subset collected from the genebank of the International Center for Agricultural Research in the Dry Area (ICARDA). This collection was selected by using the focused identification of germplasm strategy (FIGS). The subset included 138 genotypes which have been screened in the open field (Arish, Sinai, Egypt) and in the greenhouse (Giza, Egypt) by using the hydroponic system at $100 \mathrm{mM} \mathrm{NaCl}$ concentration. The experiment was laid out in randomized alpha lattice design in two replications. The molecular characterization was done by using sixteen SSR markers (collected from QTL conferred salinity tolerance in chickpea), 2,500 SNP and 3,031 DArT markers which have been developed and used for association study. The results indicated significant differences between the chickpea genotypes. Based on the average of the two hydroponic and field experiments, seven tolerant genotypes IGs (70782, 70430, 70764, 117703, 6057, 8447 and 70249) have been identified. The data analysis indicated one SSR (TAA170), three DArT (DART2393, DART769 and DART2009) and eleven SNP markers (SNP2021, SNP1268, SNP1451, SNP1487, SNP1667, SNP2095, SNP190, SNP2247 SNP1947, SNP2331 and SNP948) were associated with salinity tolerance. The flanking regions of these markers revealed genes with a known role in the salinity tolerance, which could be candidates for marker-assisted selection in chickpea breeding programs.

\section{Introduction}

About 7.5 billion human share the same land, food and water resources. The global food demands are exponentially expanded while; the water scarcity will affect 1.8 billion people in 2025. One of the most crucial problems that face food security is salinity. According to FAO, over $6.5 \%$ of the world's land is affected, which is translated into 800 million HA of arable lands and expanding dramatically ${ }^{1}$. Filling the gap between the consumption and production require more research in order to enhance unprepared economic plant varieties to face such sudden environmental changes and unlock their ability to tolerance.

Chickpea is one of the candidate cereal crops, which provides food with high nutritional 
value for an expanding world population. In addition, its global annual production is over 12 million tons. The chickpea production is centered in China (17\%), India (12\%), Russia and the USA $(8 \%)^{2}$. Chickpea is sensitive to salinity which reduces its yield greatly ${ }^{3}$.

Upon exposure to salt stress, the meristems accumulate salts in the vacuoles of the xylem ${ }^{4}$, to lower their osmotic potential till reaching high concentrations ${ }^{5,6}$. Other strategies to tolerate salinity can be by efficient osmotic adjustment, homeostasis, retention in root and mesophyll cells, and ROS detoxification ${ }^{7,8}$. The sodium $\left(\mathrm{Na}^{+}\right)$accumulation in the cytoplasm dehydrates the cell by causing ion homeostasis imbalance that inhibits enzyme activity causing cell death and toxicity ${ }^{4}$. Salinity could affect the activity of the antioxidant enzymes, $\mathrm{H}_{2} \mathrm{O}_{2}$ content, chlorophyll fluorescence $(\mathrm{Fv} / \mathrm{Fm})$, quantum yield of PSII and the rate of lipid peroxidation in leaf and root tissues ${ }^{9}$. The morphological effect of salinity on the roots was reported to be agravitropic growth of roots, i.e., growth in diameter rather than length which could reduce plant growth rate by $20 \%$, shoot biomass by $28 \%$ and seed yield by $32 \%{ }^{10,11}$.

The complexity of plant gene network makes it hard to procure a single gene with the main responsibility for salinity tolerance in the tolerant cultivars. Although most of the genes clasp with each other through the vast pool of plant biological pathways, triggering one would not mean that there will be no necessity to stimulate the others. A plethora of genes or gene families were reported to have a direct affinity with tolerant plants in response to salinity. Such genes play a role in the physiological or morphological response that the plant system uses as an outlet. Genes such as high-affinity $\mathrm{K}^{+}$transporter $(\mathrm{HKT}), \mathrm{Na}^{+} / \mathrm{H}^{+}$antiporter, $\mathrm{Na}^{+} / \mathrm{Ca}^{2+}$ exchanger are related to ion homeostasis. Serine/threonine protein kinase, peroxidase, calcium-dependent NADPH oxidase gene families are genes related to abiotic stress ${ }^{10,12-15}$. However, the gene regulatory system could have the higher hand in some cases. The DREB gene family regulates the expression of many stress-inducible genes mostly in an ABA-independent manner in addition to playing a critical role in improving the abiotic stress tolerance of plants by interacting with a DRE/CRT cis-element in the promoter region of various abiotic stress-responsive genes and other TF families ${ }^{10,16}$.

On the other hand, the massive growth in phenotypic and genotypic assessment technologies has encouraged dissecting genomic loci responsible for crop saline tolerance, in order to improve and enhance cultivated varieties. Researchers' interest in improving, profiling and mapping salinity tolerance loci has exponentially increased. Classical molecular marker technologies such as simple sequence repeats (SSR) has proved its value in detecting, tagging and identifying salinity tolerance loci in different plant species such as wheat ${ }^{17,18}$, rice ${ }^{19,20}$ and chickpea $^{21,22}$.

Due to their abundance in genomes, evolutionary relationship, suitability for genetic diversity analysis and association with complex phenotypic traits, SNP markers have gained remarkable value in plant molecular genetics ${ }^{23}$. Genome-wide association study (GWAS) through SNP genotyping has a great impact on identifying genetic regions associated with quantitative and complex traits. GWAS has been used in studying and dissecting genetic construction for salinity tolerance in Rice ${ }^{24}$, Soybean ${ }^{25}$, Sesame ${ }^{15}$, Barley ${ }^{26}$ and Rapeseed ${ }^{27}$. 
The increase in the plant whole genome annotation provides a golden opportunity to weigh traitassociated SNPs according to their potential effects in gene regulation. Such combination between phenotypic and genotypic effects could unravel unseen responsibilities for genomic variations, connect unrelated traits and promotes promising SNPs for high throughput genotyping or genome-editing technologies. Studying trait-associated SNPs was reported in pursuing genes related to 100 seed weight, root/total plant dry weight ratio ${ }^{28}$, tolerance to herbicide ${ }^{29}$, tolerance to Ascochyta blight ${ }^{30}$, tolerance to drought and heat ${ }^{31}$ in chickpea.

In order to reduce genome complexity, many methods have been developed. The DArT assay provides a remarkable advantage via an inventive selection of genome fraction corresponding predominantly to active genes (http://www.diversityarrays.com/dart-applicationdartseq). DArT has been applied for QTL mapping in Rapeseed ${ }^{32}$, Wheat ${ }^{17,33}$ and Barley ${ }^{34,35}$ and for population structure in A. tauschii ${ }^{36}$.

The localization of salinity tolerance related loci in chickpea has been reported in few research articles, such as, ${ }^{21}$ that reported two key genomic regions on $\mathrm{Ca} 5$ and on $\mathrm{Ca} 7$, that harboured QTLs for six and five different salinity tolerance associated traits, respectively. Based on the gene ontology annotation, they roughly identified forty-eight putative candidate genes responsive to salinity stress on CaLG05 (31 genes) and on CaLG07 (17 genes). Most of the genes were known to be involved in achieving osmoregulation under stress conditions. In addition, ${ }^{10}$ used differential expression gene analysis to detect abiotic stress-related genes that significantly were up-regulated in the tolerant genotypes and were down-regulated in the sensitive genotypes under salt stress.

The plant mechanism for both salinity and drought require the activation of genes responsible for the plant cellular adaptation, the cell wall maintenance, the protection against water loss and the cellular ionic and osmotic homeostasis ${ }^{37}$. This relationship between salinity and drought was employed in different plant molecular genetics researches, thus drought tolerance responsible loci could be used to expand the research in salinity and vice versa ${ }^{38-41}$. In a breeding Chickpea population resulted from a cross between ICC4958 and Annigeri, two loci on LG4, were found to be associated to drought tolerance ${ }^{42}$.

In order to, improve the efficiency with which specific adaptive traits are identified from genetic resource collections the Focused Identification of Germplasm Strategy (FIGS) was designed based on the premise that the environmental selection pressures from which these germplams was originally sampled will be reflected on them ${ }^{43}$. FIGS uses both trait and environmental data to define a set of accessions with a high probability of containing the desired traits based on a quantification of the trait-environment relationship ${ }^{44-46}$. FIGS has been successfully used to screen new genes related to abiotic and biotic stresses in different plant species $43,47-49$.

In the present study, authors used FIGS protocol to construct a chickpea diversity panel that contains landraces and wild chickpea accessions with a potential salt stress tolerance. In addition to comparing the performance of one dominant (DArT) and two co-dominant (SSR and SNP) genetic markers in studying the relatedness coefficients between these genotypes, 
population patterns and gene diversity. The molecular markers associated with chickpea salinity tolerance were studied according to their genetic effect and their gene closeness through SNP effect and In silico PCR analysis. Previously published salinity and drought tolerance associated SSR markers were studied through In silico PCR analysis in order to identify closed genes. All the potential genes were studied according to their gene pathways and the relatedness to chickpea salinity tolerance.

\section{Plant Material}

The studied germplasm panel is composed of 203 different genotypes that were collected from 28 provinces in 13 countries across the globe. The seeds were provided by the gene bank of ICARDA by using FIGS tool (TABLE S1). Most of the chickpea panel is from Pakistan and India provinces which are thought to have saline environments. 138 genotypes were used in both the hydroponic and field environments.

\section{Salinity tolerance of chickpea genotypes}

The experiments were performed in the field (Arish, Sinai, Egypt) and in the greenhouse by using the hydroponic system (Agricultural Research Centre, Giza, Egypt), in November 2014. The individuals were replicated two times and arranged in an alpha lattice randomized block design. A dripping water irrigation system was installed to water the field every two weeks. In the greenhouse, one seed of individual accession was sown in a tray $(10 \mathrm{~cm}-30 \mathrm{~cm})$ containing a mixture of peat moss $(40 \%)$ and perlite $(60 \%)$. After two weeks of germination, the seedlings were transferred to hydroponic tank $\left(150 \mathrm{~cm} \_230 \mathrm{~cm}\right)$ with half strength of a nutrient solution.

To determine the salt concentration in the soil of the field, a soil sample was air dried, softened and sieved prior to preparing soil pest then soil solution was extracted to determine $\mathrm{pH}$, and the concentration of cations and anions (Page, 1982). The salt concentration of the hydroponic tank was adjusted at $100 \mathrm{mM}$ and the $\mathrm{pH}$ was adjusted at 8 , both of them were checked daily. Salinity stress tolerance trait was evaluated as the necrosis score. The scoring was conducted at a relatively early stage of salt treatment when the necrotic symptoms appeared on the stem and the leaves, after one week. The phenotypic scaling was set from 1 to 5 , where the tolerant plant was given score number 1 , and the sensitive plant was given score number 5. And when the plant is partly tolerant, it was given number 2, 3 or 4 according to the intensity of the necrosis. The phenotypic reading of the greenhouse was taken every three weeks during the experiment time. For the field experiments, the phenotypic readings were taken every two months. One way ANOVA was performed to test the significance of both the field and the greenhouse phenotypic data. Consequently, the average data was used for further analysis. Figure 4 shows the frequency distribution of salinity tolerance among plant genotypes.

\section{DNA Extraction}

About $0.1 \mathrm{gm}$. of fresh tissue was ground by liquid nitrogen using mortar and pestle. Then 1 ml. CTAB was added to the ground samples and mixed well to be incubated for 1 hour at $65{ }^{\circ} \mathrm{C}$. $1 \mathrm{ml}$. chloroform: Isoamyl (24:1) was added to the samples and the mixture was shaken for 20 minutes. Then the samples were centrifuged for 15 minutes, and the supernatant was transferred to a new tube. $1 \mathrm{ml}$ of absolute cold isopropanol was used to precipitate the DNA. Then the 
samples were centrifuged. The pellet was washed twice with $70 \%$ ethanol. The samples were airdried and eluted in $200 \mu 11 \mathrm{X} \mathrm{TE}^{50}$.

\section{Molecular Markers}

Sixteen SSR primers have been used in this study. TABLE 1 represents the review of literature of the polymorphic SSR markers. SSR PCR reactions were performed in $15 \mu 1$ reaction volume consisting of $5 \mathrm{ng}$ DNA template, 10 picomol of forward primer, 10 picomol of reverse primer, $0.1 \mathrm{U}$ of Taq DNA polymerase, $25 \mathrm{mM}$ of $\mathrm{MgCl}_{2}, 2 \mathrm{mM} \mathrm{dNTPs}$ and 10X PCR buffer in 96-well microtitre plates using thermal cycler. PCR program was used to amplify DNA fragments as follow: initial denaturation was $5 \mathrm{~min}$ at $95^{\circ} \mathrm{C}$. This was followed by 35 cycles of denaturation for $15 \mathrm{sec}$ at $95^{\circ} \mathrm{C}$, annealing for $15 \mathrm{sec}$ at $55^{\circ} \mathrm{C}$ and extension for $30 \mathrm{sec}$ at $72^{\circ} \mathrm{C}$. Subsequently, $7 \mathrm{~min}$ final extension at $72^{\circ} \mathrm{C}$. SSR markers were checked for amplification on 9 $\%$ acrylamide gel.

The Diversity Arrays Technology (DArT®) markers panel was used to genotype chickpea population with high-density. Out of 203 different genotypes that were collected, 186 genotypes were sent for DArT, using $50 \mu \mathrm{l}$ of a $100 \mathrm{ng} \mu \mathrm{l} / 1 \mathrm{DNA}$ of each sample. The DNA was sent to Triticarte Pty. Ltd. Australia (http://www.triticarte.com.au) for DArT markers genotyping (Chickpea DArTseq panel version 1.0) and SNP genotyping as a provider for commercial service. A 3031 DArT and 2499 SNP polymorphic marker loci with quality parameter and call rate both greater than $80 \%$ and minor allele frequency (MAF) $>5 \%$ were selected for genomewide association analysis.

BLAST tool ${ }^{51}$ was used to assign SNP and DArT markers to chickpea chromosomes. DArT markers were assigned to all chickpea chromosomes, where $\mathrm{Ca} 4$ has the highest number of DArT markers (755), Ca8 has the lowest number (127) and 69 markers has unknown position (Ca9). For SNP, Ca4 has the highest number of markers (632), while Ca8 has the lowest number (127) and 13 makers with unknown location (Ca9). The marker density in DArT assay ranged from $17(\mathrm{Ca} 6)$ to 54 markers/Mpb (Ca3), while in SNP assay it ranged from 19 (Ca8) to 48 (Ca7) marker/Mpb (Ca4) (TABLE2).

\section{Molecular marker analysis}

Genetic distances (GD) and Nei's gene diversity ${ }^{52}$, were calculated for each locus separately for every marker type. Based on the GD matrices, phenograms of the 186 samples were constructed with the Unweighted Pair Group Method with Arithmetic means (UPGMA) by Power marker software ${ }^{53}$. The association between SSR markers and salinity stress tolerance was performed through F-test for each marker to test its linkage to the salinity stress tolerance through PowerMarker software ${ }^{53}$. Spoon in silico PCR program (http://www.ageri.sci.eg/index.php/facilities-services/ageri-softwares/spoon) was used to identify the location of SSR marker loci previously published and used through study, these SSR markers are known to be linked to salinity or drought tolerance in chickpea. While, The association of the SNP and the DArT markers with salinity stress tolerance was performed by using GAPIT (R Package) ${ }^{54}$. SNP and DArT markers which have been used for further analysis, have a significance score higher than higher than 0.0001 in both open field and greenhouse. The effect 
of SNPs linked to salinity tolerance has been studied through SnpEFF ${ }^{55}$. The chickpea genome 56 has been used through all marker-gene analysis. Genes near/adjoin salinity associated molecular markers have been used for gene enrichment analysis, the gene pathways for these genes have been determined by KEGG pathways database ${ }^{57}$ using BlastKOALA tool ${ }^{58}$. Circos configuration ${ }^{59}$ was used to illustrate the location of the significant molecular markers and candidate genes, from which the distance between the QTL and the gene can be assumed. The iTOL online web tool ${ }^{60}$ was used to draw phylogenetic trees, while ClustVis ${ }^{61}$ was used to construct population structure kinship illustration.

\section{Discussion}

Chickpea is widely grown in West and Central Asia and Australia, where saline soils are abundant. There is narrow genetic variation among different genotypes, which is an obstacle for breeding for salinity tolerance. In chickpea, despite the conductance of several mapping studies, only two studies have reported the presence of QTLs for salinity tolerance. There is no report on putative candidate genes that would confer salinity tolerance in chickpea ${ }^{21}$.

\section{Soil analysis of field experiment in Arish}

The chickpea evaluations for salinity tolerance were made across the years 2014 and 2015 through field and greenhouse experiments. The field trial was made in the open field (Arish, Sinai, Egypt). The salt concentration in the field was $344 \mathrm{ppm}$ in the first $30 \mathrm{~cm}$ depth, $904 \mathrm{ppm}$ in the depth from 30 to $60 \mathrm{~cm}$, and $848 \mathrm{ppm}$ in the depth of more than $60 \mathrm{~cm}$. The analysis of the water of irrigation revealed that the average of the salt concentration was 897 $\mathrm{mM}$, and the $\mathrm{pH}$ was 7.2.

\section{Phenotypic analysis for salinity tolerance}

The plant which takes reading till 3.25 was considered to be tolerant. The plant which takes 5 as necrosis scale was considered to be highly sensitive (died by stress). Forty-seven accessions were observed to be tolerant and 3 accessions were highly sensitive to salinity stress. The salinity tolerance was normally distributed among chickpea genotypes (FIGURE 4). A 138 genotypes were successfully screened in the field and the greenhouse (Arish, Egypt and hydroponic). No significant difference has been observed between the two methods. Significant differences have been identified between the genotypes where CV\% and LSD was 7.8 and 1.27, respectively.

The phenotypic evaluation showed significant variations for salinity stress tolerance under saline conditions between various genotypes indicating a broad phenotypic variance within the global chickpea population. Based on the average from the two hydroponic and field experiments, seven tolerant genotypes IGs (70782, 70430, 70764, 117703, 6057, 8447 and 70249 ) have been identified (TABLE 3). The present data indicated the presence of genetic components influencing salinity tolerance traits. Using ANOVA, we found significant constancy of the salinity stress tolerance trait suggesting the genetic control of this trait as seen in (TABLE 4). It was observed from the tables that among the seven most tolerant genotypes, six of them are from Pakistan, and one from Azrabejan.

\section{Simple sequence repeat analysis}


Polymorphic SSRs are excellent molecular markers, because of their multi-allelism, genome abundance, co-dominance and high polymorphic rate. Additionally, compared to high throughput molecular markers such as SNPs, SSRs have their own advantages respected to population genetics ${ }^{62}$. The association between SSR markers and abiotic stresses tolerance such as salinity has been recognized and discussed in different plant species ${ }^{39,63}$. One of the main importance of the SSR markers, the inheritance of its alleles from the parents to the progeny which made them an efficient tool in marker-assisted selection breeding programs.

Sixteen SSR markers were applied in this study, these markers have shown linkage to salinity tolerance from previous literature (TABLE T1). The polymorphism information content (PIC) detect the ability of the marker to find the genetic variation among the used diversity set. In addition, the PIC is a measure of the marker informativeness and it ranges from 0 to 1 . The markers with a PIC higher than 0.5 are highly informative, while, a PIC value between 0.5 and 0.25 implies a locus of moderate informativeness ${ }^{64}$. The PIC value in the present study ranged from 0.3 (H1H13) to 0.9 (TAA170).

The marker-trait association analysis for SSR markers was calculated separately using greenhouse and field data. Additionally, the analysis of variance (ANOVA) was calculated for greenhouse and field results. The significance score for the association between SSR markers abundance and greenhouse data, ranged from 0.006 (TAA170) to 1 (TA179), while with field data, it ranged from (0.06) (TAA170) to 0.9 (TR31), with ANOVA score ranged from 0.02 (TAA170) to 0.9 (TA179). The significant association between TAA170 and salinity stress tolerance indicates a potential role in saline tolerance control. Table 5 represents the sixteen polymorphic SSR markers used in this study and their association with the salinity stress tolerance in the hydroponic experiment in the greenhouse and Arish's field environments.

SSR phylogenetic analysis clustered chickpea genotypes into two separated clusters. On the origin level, SSRs were almost successful to combine Pakistani and Indian genotypes. Most of the tolerant chickpea genotypes were clustered in the first clusters, while moderately tolerant genotypes were clustered in the second major cluster (FIGURE1).

In silico PCR is a computational procedure that estimates PCR results theoretically using a given set of primers to amplify DNA sequences from a sequenced genome or transcriptome ${ }^{65,66}$. This procedure could offer the ability to explore and detect QTLs nearest genes, in order to study their potential relationship with traits of interest. Several QTLs which have been acquired through SSR markers, showed a significant relationship with abiotic stresses such as salinity and drought in chickpea, where the association between these loci and their corresponding traits was presented through field trials and lab experiments. In order to study and explore chickpea genes nearby our and previously published chickpea salinity tolerance QTLs, the in silico PCR analysis was conducted on our lab-tested SSR markers in addition to previously published chickpea SSR markers to study and explore the chickpea nearby genes (TABLE 1).

In silico PCR analysis revealed that 15 SSR markers were closely located near 19 chickpea genes with a distance ranged from $6 \mathrm{bp}$ to $7 \mathrm{kbp}$ (TABLE 6). According to UniProtKB (www.uniprot.org), which is a central hub for the collection of functional information on 
proteins, the gene ontology analysis showed that, at the molecular function level some of these genes belong to phosphorelay sensor kinase activity (1), DNA binding transcription factor activity (1), catalytic activity (12) and binding (8). While, at the cellular component level, some shows a relationship to Golgi membrane (1), mitochondrial matrix (1), integral component of membrane (5), protein-containing complex (2), organelle (1), organelle part (2) and cell part (5). Additionally, on the biological process level some genes belong to metabolic process (4), cellular process (4) and cell wall organization (1).

SSR markers illustrated a close distance to some important chickpea genes; most of these genes have a direct or indirect relationship to salinity and drought tolerance. These genes included DLAT, ASK8, GAUT1, MOCS2, OXI1, CKI1, PERK9, DREB2F, STN7, TMED2 and CRK25 (TABLE6 and FIGURE5).

DLAT (Dihydrolipoyllysine-residue acetyltransferase) is a component of pyruvate dehydrogenase complex (PDC) in mitochondria and a member of pyruvate metabolic pathway. The PDC catalyzes the overall conversion of pyruvate to acetyl-CoA and CO2 and thereby links the glycolytic pathway to the tricarboxylic cycle ${ }^{67}$. Taylor et al., ${ }^{68}$ reported that environmental stress causes oxidative damage to the mitochondria leading to inhibition of glycine decarboxylase. The participation of pyruvate dehydrogenase in plant response to abiotic stresses was reported in drought, chilling and salinity stresses ${ }^{69}$.

The salinity stress could affect the plant growth and development ${ }^{70}$. ASK8 or ASK $\theta$ which belongs to the SHAGGY/GSK-3 family plays an important role in serine/threonine kinase activity, which is involved in cell differentiation. The SHAGGY/GSK-3 family was strongly suggested to be involved in stress responses and ASK $\theta$ may have a role in the regulation of transcription factors in Arabidopsis ${ }^{71}$. Recent studies have revealed that plant GSK3 proteins are actively implicated in hormonal signaling networks during development as well as in biotic and abiotic stress responses, especially in osmotic stress responses ${ }^{72,73}$. Additionally, the over expression of GSK1 influences $\mathrm{NaCl}$ stress responses in the absence of $\mathrm{NaCl}$ stress and develops enhanced tolerance $\mathrm{NaCl}$ tolerance in Arabidopsis ${ }^{74}$.

Galacturonosyltransferase (GAUT) is a type of $\alpha$-1,4-galacturonosyltransferase that can transfer galacturonic acid from uridine 5'-diphospho-galacturonic acid into the pectic polysaccharide homogalacturonan ${ }^{75}$. Reported mutations in the genes belonging to GAUT family resulted in discernible changes in cell wall monosaccharide composition ${ }^{76}$. GAUT1 and GAUT7 are the main components of cell wall pectin biosynthetic homogalacturonan galacturonosyltransferase complex in plants, where GAUT1 is involved in homogalacturonan (HG) synthesis ${ }^{77}$.

Molybdenum cofactor (MoCo) biosynthesis is a highly conserved biochemical pathway resulting in the biochemical activation of molybdenum after binding the dithiolene moiety of a small organic compound called molybdopterin ${ }^{78}$. MOCS2 is the catalytic subunit of the molybdopterin synthase complex and acts as a sulfur carrier required for molybdopterin biosynthesis ${ }^{79-81}$. It was found that Mo deficiency affects plant nitrogen and sulphur metabolisms, in a manner similar to the nitrate assimilation activity which is inhibited by the 
shortage of Mo-co, but still different from nitrate or sulphate limitation ${ }^{80}$.

In response to stimuli and during development of active oxygen species (AOS), genes are generated to function as signalling molecules in order to generate specific downstream responses in eukaryotes ${ }^{82}$. In A. thaliana, OXI1 kinase is necessary for oxidative burst-mediated signalling in stress response, where OXI1 encodes serine/threonine kinase which is induced in response to a wide range of $\mathrm{H}_{2} \mathrm{O}_{2}$-generating stimuli ${ }^{82,83}$. Additionally, OXI1 controls singlet oxygen-induced cell death in A.thaliana under high-light stress ${ }^{84}$ and is up-regulated in fungus-infected A.thaliana roots ${ }^{85}$.

In order to regulate female gametophyte development and vegetative growth in Arabidopsis, the histidine kinase CKI1 acts upstream of histidine phosphotransfer proteins ${ }^{86}$. On the other hand, the putative Arabidopsis sensor histidine kinases were originally classified as a candidate cytokinin receptor, based on the fact that overexpression of CKI1 in Arabidopsis hypocotyl segments resulted in callus proliferation and shoot differentiation in the absence of exogenously supplied cytokinin and auxin ${ }^{87}$. There is structure and binding specificity of the receiver domain of sensor histidine kinase CKI1 in A.thaliana where, there are three cytokinin receptors, HK2, HK3 and HK4/CRE1, one putative osmosensing HK, HK1, and two cytokinin independent HKs, CKI1 and CKI2/AHK5 ${ }^{88}$. In Arabidopsis, these nonethylene receptor histidine kinases are stress-responsive and have a role in the regulation of plant response to abiotic stress such as drought and salt stress responses ${ }^{89}$.

In plants, as in other eukaryotes, a diverse group of cell surface receptor-like protein kinases (RLKs) play a fundamental role in signal transduction processes. More than 600 genes belong to the receptor-like kinase (RLK) family. In Arabidopsis, among these RHS genes, RHS10, which encodes a proline-rich extensin-like receptor kinase (PERK), has a negative role in root hair elongation or tip growth ${ }^{90,91}$. In the early steps of osmotic-stress signalling, several RLKs localized to the plasma membrane are involved in different plant species and recently have been suggested to be involved in the turgor pressure perception ${ }^{92}$.

The transcription factors group DEHYDRATION-RESPONSIVE ELEMENT-BINDING PROTEIN 2 (DREB2) contribute to stress tolerance by initiating transcription through the ciselement dehydration-responsive element (DRE) in response to stress stimuli and its expression is induced by heat shock, dehydration and high salinity ${ }^{93,94}$. Overexpression of DREB2 isolated from lotus, improves salt tolerance in transgenic A.thaliana ${ }^{95}$. Additionally, a comprehensive analysis of rice DREB2-type genes that encode transcription factors reported that it is involved in the expression of abiotic stress-responsive genes. Moreover, the over-expression of DREB2 led to higher salt resistance than that of the wild-type plants, higher germination rates and better root growth in rice ${ }^{96}$.

The chloroplast serine-threonine protein kinase (STN7) is required for the phosphorylation of the light-harvesting system of photosystem II and for the state transitions in Arabidopsis. The state transitions is a process that allows a balance between photosystem II and photosystem I through light excitation energy in the photosynthetic machinery and thereby optimizing the photosynthetic yield ${ }^{97}$. Furthermore, it operates in retrograde signalling through 
controlling redox balance in the electron transfer chain and in short term responses via phosphorylation of a thylakoid bound phosphoprotein ${ }^{98,99}$.

The secretory pathway is of a vital importance in most eukaryotic cells and has an essential role in a large variety of bioactive molecules synthesis, transport and secretion. These molecules participate in intercellular communication ${ }^{100}$. The transmembrane emp24 domaincontaining protein (TMED)/p24 gene family contribute to the vesicular trafficking of proteins, Golgi dynamics, as well as intracellular protein trafficking ${ }^{101}$. Furthermore, for some p24 family members, additional roles in the post Golgi compartments of the secretory pathway have been recently proposed ${ }^{100}$ and it was reported to be upregulated under environmental stresses such as heat shock ${ }^{102}$.

In the past few years, some CRKs (cysteine-rich receptor-like kinases ) were reported to play a critical role in biotic and abiotic responses in Arabidopsis, such as ABA signaling, disease resistance, plant growth, cell death and response by extracellular ROS production ${ }^{103-105}$. CRKs are required in rice NH1 (NPR1)-mediated immunity ${ }^{104}$ and in Arabidopsis which is protected against apoplastic oxidative stress ${ }^{106}$ also it enhanced its pattern-triggered immunity by being overexpressed ${ }^{105}$. Additionally, some genes belong to CRKs family act as a positive regulator of plant tolerance to salt stress ${ }^{107}$.

\section{DArT assay}

Compared to co-dominant SSRs and SNPs markers, DArT is a bi-allelic dominant marker, therefore; provides less genetic information ${ }^{108}$. On the other hand, due its easy development it could provide a viable alternative for estimating the relation between various genotypes ${ }^{109110}$. DArT technology was successfully applied in population genetics in order to detect useful loci associated with salinity tolerance in barley ${ }^{35,111,112}$ and bread wheat ${ }^{17,113}$.

In this research, we have used 3031 DArT markers. The maximum value of PIC was 0.375 and the minimum was 0.01 with an average of 0.13 , which implies a locus of moderate informativeness ${ }^{64}$. On the other hand, the maximum dissimilarity revealed with DArT markers was 0.2 and the minimum was 0 , while the median was 0.012. DArT markers clustered chickpea genotypes into two clusters where the first cluster was divided into three subclusters and the second cluster was divided in four different clusters where G128434 was clustered in one cluster (FIGURE 2). Compared to the SSR phylogenetic tree, DArT markers were more comprehensive and showed more variation between different genotypes. MLM GWAS analysis ${ }^{114}$ was used to detect salinity associated DArT markers. Only three DArT markers (DART2393, DART769 and DART2009) showed a significant score. According to UniProtKB (www.uniprot.org), the two genes belong to catalytic activity also they are involved in cellular metabolic processes. DArT markers, DART2009 and DART769 were close to HIS3 and HIBCH which are located on Chr7 (TABLE 7 and FIGURE 5).

Histidine is an essential dietary nutrient for animals, but it is synthesized de novo by plants and microorganisms. Imidazole glycerol-phosphate (IGP) dehydratase is involved in the histidine biosynthesis pathway. Thus, the pathway of histidine biosynthesis is a potential target for herbicide development ${ }^{115}$. 
3-hydroxyisobutyryl-CoA (HIBYL-CoA), a saline catabolite, has high activity toward isobutyryl-CoA ${ }^{116}$ and its association with fatty acid biosynthesis or metabolism was also reported ${ }^{117}$. The HIBYL-CoA is differentially expressed in the peanut roots in response to drought-responsive ${ }^{118}$.

\section{SNP assay}

SNP markers are more informative than classical molecular markers, it provides more comprehensive information about genetic mutations that is responsible for trait variability among different plant genotypes. SNP genotyping assay has been successfully used to dissect salinity tolerance in soybean ${ }^{25}$ and cotton ${ }^{119}$. In this research, 2500 SNPs markers were used for chickpea genotyping. The maximum PIC value was 0.0106 and the minimum was 0.58 with an average of 0.1634 , which indicate a moderate loci informativeness. On the other hand, the maximum dissimilarity revealed by SNP markers was 0.53 , the minimum was 0.004 and the median was 0.266. SNP-based phylogenetic tree clustered chickpea genotypes G70248 and G74929 in one cluster, while other genotypes were clustered in another major cluster. About 19 chickpea genotypes were extremely close to each other with moderately salinity tolerance and mostly from India and Pakistan (FIGURE 3).

Eleven SNP markers (TABLE 7) were associated with salinity tolerance in both filed and greenhouse. Ten SNP markers were close and have a "MODIFIER" effect to 16 chickpea genes (TABLE 6 and FIGURE 5). According to UniProtKB (www.uniprot.org), the gene ontology analysis showed that, at the molecular level these genes are involved in catalytic activity(3), binding(2) and trans-membrane transporter activity (1). While, on cellular component some shows a relationship to protein-containing complex (2), membrane part (3),intracellular organelle part, (2) and cell part (3). Additionally, on the biological process level some genes belong to metabolic process (1), cellular process (2), regulation of biological process (1) and localization (1). Some of these genes have a known direct or indirect impact on salinity tolerance in plants as follow;

NIPBL-like Plays an important role in the loading of the cohesin complex on to DNA and forms a heterodimeric complex (also known as cohesin loading complex) with MAU2/SCC4 which mediates the loading of the cohesin complex onto chromatin ${ }^{120,121}$.

MAP-NDL is one of the major plant responses against salt stress that include microtubule depolymerization and reorganization, which is predicted to be pivotal for plant survival under abiotic stress ${ }^{122}$. Microtubule organization is regulated by microtubule-associated proteins (MAPs) ${ }^{123}$, of which MAP-NDL is a plant-specific protein that interacts with microtubules and regulates dynamics of microtubule ${ }^{122}$ and may play a role in the anisotropic cell expansion and organ growth ${ }^{124,125}$. Additionally MAP70-5, a divergent member of the MAP70 family of MAPs, is required for anisotropic cell growth in Arabidopsis and its overexpression causes epidermal cells to swell, induces right-handed organ twisting and maintain axial polarity to ensure the regular extension of plant organs ${ }^{124}$.

P67 (a.k.a SUPPRESSOR OF VARIEGATION 7 (SVR7)) belongs to pentatricopeptide repeat (PPR) family, which contains 450 members and make up a significant proportion $(6 \%)$ of 
the unknown functional proteins in Arabidopsis ${ }^{126}$. They are defined by the presence of a canonical 35-amino-acid motif, repeated in tandem up to 30 times ${ }^{127}$. The PPR proteins are considered to react with specific RNA in the cellular organelles and play a role in RNA processing or translation ${ }^{128}$. It has been reported that they are involved in the splicing effects during the chloroplast development and the abiotic stress response in rice. A characterized mutant displays chlorotic striations in the early development, enhanced sensitivity to ABA and salinity and accumulation of more $\mathrm{H}_{2} \mathrm{O}_{2}$ than the wild-type ${ }^{129}$. The Arabidopsis nuclearlocalized PPR protein SVR7 is essential for the translation of the chloroplast ATP synthase subunits. SVR7 mutants were shown to accumulate higher levels of ROS and display increased sensitivity to $\mathrm{H}_{2} \mathrm{O}_{2}$ with decreased photosynthetic activity ${ }^{130}$.

PUB9 belongs to ubiquitin (Ub) targeting proteins. It plays an important role in the degradation of proteins by the proteasome through polyubiquitination of substrate proteins via an enzyme cascade consisting of activating (E1), conjugating (E2) and ligating (E3) enzymes ${ }^{131,132}$. It participates in several events in the life of the plant such as a hormone and biotic/abiotic stress signaling pathways ${ }^{133}$. It functions as an E3 ubiquitin ligase and may be involved in the abscisic acid mediated signaling pathway at least during the germination stage ${ }^{134}$. Its over-expression has been reported in root transcriptome analysis in grape genotypes with contrast translocation pattern of excess manganese from root to shoot ${ }^{135}$.

Translocase of Outer Mitochondrial Membrane 6 (TOMM) is a component of the complex that is responsible for cytosolically synthesized mitochondrial pre-proteins ${ }^{136}$. In Saccharomyces cerevisiae, seven TOMM genes associated with mitochondrial biosynthesis were significantly repressed after heat treatment ${ }^{137}$.

Ubiquitination, the reversible protein conjugation with ubiquitin (Ub), is a posttranslational modification that enables rapid and specific cellular responses to stimuli, without requirement of de novo protein synthesis. It has a central role in regulating many key cellular and physiological processes, including responses to biotic and abiotic stresses ${ }^{138,139}$. The Ubiquitinproteasome system (UPS) plays a central role in the efficient perception of different environmental stresses by suppressing stress signaling pathways during favorable growth conditions and thus, eliminating negative regulators of signaling responses to a stimulus ${ }^{140,141}$.

Arabidopsis thaliana TRANSPARENT TESTA 12 (AtTT12) encodes a multidrug and toxic compound extrusion (MATE) transporter that contributes in seed coat pigmentation and functions as a vacuolar flavonoid/H+-antiporter that accumulates Proanthocyanidins in cells 142,143. Moreover, it has a role in the environmental stress tolerance ${ }^{144}$. The upregulation of TESTA12 was reported in mechanisms of salt stress tolerance in R. stricta ${ }^{145}$ and heat stress tolerance ${ }^{146}$.

DNA-(apurinic or apyrimidinic site) lyase 2 (APEX2) works as a weak apurinic/apyrimidinic (AP) endodeoxyribonuclease in the DNA base excision repair (BER) pathway of DNA lesions that is induced by oxidative and alkylative agents. The presence of metal binding sites (MBS) is a typical feature of these proteins ${ }^{147,148}$. The over-expression of AP has been thought to be responsible for enhancing osmotic stress tolerance in Medicago truncatula 
148. The AP lyase-dependent pathway to repair sites could generate new phenotypes and mutations ${ }^{149}$. Additionally, it was reported that in Arabidopsis, the DNA glycosylase/lyase has an active role in DNA demethylation of ROS1, which possesses several enzymatic activities ${ }^{150}$ and some AP genes function downstream of ROS1 in a ZDP-independent branch of the active DNA demethylation pathway in Arabidopsis ${ }^{151}$.

MED4 is a mediator, which is a necessary component for RNA Pol II-mediated transcription of genes, where they play crucial roles in the basic process of transcriptional regulation of eukaryotic genes ${ }^{152}$. In Arabidopsis, it was reported that some Med genes affect cell number and shoot meristem development ${ }^{153}$, floral organ identity ${ }^{119}$, embryo patterning and cotyledon organogenesis ${ }^{154}$. Additionally, MEDs have been shown to play a role in biotic or abiotic responses, by the virtue of its ability to interact with several key transcriptional regulators 155,156. Moreover, in Arabidopsis, Med4 along with other Med genes showed more than 2-fold increase in their transcript abundance in response to the presence of $\mathrm{NaCl}$ in the media ${ }^{152}$.

VPS39 (vam6/Vps39-like) is a complex, in which Vam6p/Vps39p stimulates guanine nucleotide exchange on small guanosine triphosphatase (GTPase) Vam4p/ Ypt7p and activates it, which in turn plays a vital role in tethering through the association with class CVps complex ${ }^{157 .}$ it was upregulated and differentially expressed in secretome of TiK, the highly virulent $\mathrm{T}$. indica 158

Various key factors/regulators and transcription factors (TFs) play a critical role(s) towards regulating the gene expression patterns in response to stress conditions to cope with biotic and abiotic stresses ${ }^{159}$. OsHBP1b TF belongs to the bZIP family and localized within the Saltol QTL, its expression is induced upon salinity treatment in seedlings, where it maintains chlorophyll content and improves the antioxidant machinery ${ }^{160}$.

CHOLINE TRANSPORTER-LIKE1 (CTL1) is involved in choline transport process in addition, it functions in sieve plate and sieve pore formation in plants, where a mutation in this gene could cause several phenotypic abnormalities, including reduced pore density and altered pore structure in the sieve areas associated with impaired phloem function ${ }^{161}$.

Kinesin-5 is a molecular motor protein that is essential in mitosis and exists in plant, animals and yeast ${ }^{162-164}$. Plants possess a large repertoire of microtubule-based kinesin motor proteins. The distinctive inventory of plant kinesins suggests that kinesins have evolved to perform specialized functions in plants ${ }^{165}$. Kinesin-5 is necessary for cortical microtubule organization and its loss severely compromises spindle structure and cytokinesis. Additionally, the kinesin-5 motor is crucial for mitosis in Arabidopsis roots and a mutant allele in this gene causes severe cell division defects in pollen development and embryogenesis ${ }^{166}$.

\section{The relationship between SSR, DArT and SNP assays}

Kinship analysis depending on DArT and SNP markers separated chickpea genotypes in two major clusters, where one cluster contain most of the chickpea genotypes (FIGURE 6). By collapsing the tree branches where they have the same similarity mean, they were collapsed in 16 branches (FIGURE 7)

Mantel test as implemented in the GenAlex molecular analysis tool. It is employing 9999 
random iterations which was used to calculate correlation matrices between the three marker systems that were used in this study. The correlation between SSR and both of DArT and SNP markers produced non or very low $\mathrm{R}^{2}$, which demonstrated a very weak correlation between the SSR markers and other markers. This could be due to the small number of SSR markers used in this study (FIGURE 8 and 9). However, a positive correlation between SNP and DArT assay was revealed by Mantel test with $\mathrm{R}^{2}$ of 0.58 (FIGURE 10). Similar results were reported by Baloch et al., ${ }^{167}$ in wheat, they spotted a correlation of 0.775 between DArT and SNP markers. Except for chromosomes 6 and 8, salinity tolerance associated genes were distributed across the chickpea genome (FIGURE 5).

\section{Acknowledgements}

The authors gratefully acknowledge the financial support of International Center for Agricultural Research in the Dry Areas (ICARDA), Cairo, Egypt.

\section{Author Contributions}

S.M.A, A.M.A and A.H. analyzed all experiments' data and drafted the manuscript. S.M.A, M.H.M and H.A and conducted all greenhouse and filed experiments and the constitution of germplasm panel and its phenotyping. A.H, M.A.B, M.A.K and O.A.M participated in drafting and correcting the manuscript critically and gave the final approval of the version to be published. All authors have read and approved the final manuscript.

\section{Additional Information}

Supplementary information accompanies this paper at

Competing Interests: The authors declare no competing interests. 
bioRxiv preprint doi: https://doi.org/10.1101/519744; this version posted January 13,2019 . The copyright holder for this preprint (which was not certified by peer review) is the author/funder. All rights reserved. No reuse allowed without permission.

\section{TABLES and FIGURES}

Table 1: SSR primers' information used in this study.

\begin{tabular}{|c|c|c|c|c|c|}
\hline Name & Linkage group according to literature & Forward Sequence & Reverse Sequence & $\begin{array}{l}\text { Used in } \\
\text { silico PCR }\end{array}$ & $\begin{array}{l}\text { Used in } \\
\text { lab PCR }\end{array}$ \\
\hline GA4 & $\mathrm{LG}^{7^{22}}$ & TTGCGTGTCAATCTCATTGG & TCAACACCCCTAACTCGGAC & & \\
\hline GAA44 & LG $7^{171}$ & AGCAAGCCCATGATTTTCTC & ATGACATTCCAATCGGCTTC & & \\
\hline $\mathrm{H} 1 \mathrm{C} 22$ & $L G 7^{17 x}, L G 5^{160}$ & ATTTATACAAAGTTTTTGAAGTCG & CTTGTAAGTAGATAGTTTCACCAAA & * & \\
\hline $\mathrm{H} 1 \mathrm{HO} 07$ & $L G 7^{77}, L G 5^{75}, L G 7^{169}$ & CATCAAATAATGATGTGCTTGC & AAATTGTTGATTTTAACTAACCAAGA & & \\
\hline H1118 & $L G 7^{16, L G 7^{171}}$ & GCCATGCCAGAAAGATGTAA & GTGGCTAGAGATTGCCATGA & & \\
\hline H1N12 & $L G 7^{17}, L G 3^{17}, L G 5$ & AAAAATTGGTTCTCAAGAGTAAA & ATGAGGATTGGACGTAATCA & & \\
\hline H2B202 & $L G 7^{170}, L G 5^{169}$ & GAAATAAACATGCGTATTGCTACA & ATTTATCGGTATCTCCAACGGTAG & & \\
\hline H2101 & $L G 3^{77}, L G 1^{175}$ & AACATTCTGAACAGACACTTTTCTCTA & ПТTTCTCTTTTAACACATAGCCTTTT & & \\
\hline H2J09 & 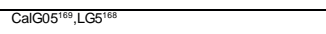 & AACGAAAAACAAGGGAGAAAAA & TATTTCTTTGACTCCCCCTAACTT & * & \\
\hline H4F07 & $L G 7^{169}, L G 5^{10}$ & AACGCCTGCATTTTATTTTTGT & GGATTCTATTCAAAGCCCAATC & & \\
\hline ICCM0178 & $\mathrm{CalG0}^{3{ }^{8}}$ & AGTTTGGGTTTCACCGCCT & GAACGCGCTCTGTTCATAAT & & \\
\hline ICCM0293 & 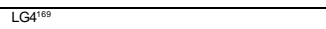 & AGTGATGCCACGAGAATTGC & CTGGTTCGGAATTGTCATCC & $\overline{7}$ & * \\
\hline STMS11 & 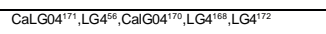 & GTATCTACTTGTAATATTCTCTTCTCT & ATATCATAAACCCCCCAC & & \\
\hline STMS22 & LG5 & CTCTTCCTCCTCGAGATC & ATAGATACAATACTCTGTGAGTTGG & & \\
\hline STMS25 & {$\left[\mathrm{LG} 7^{144}, \mathrm{LG} 3^{178}, \mathrm{LG} 4^{170}, \mathrm{LG} 5^{171}\right.$} & TACACTACTGCTATTGATATGTGGT & GACAATGCCTTTTTCCTT & & \\
\hline TA18 & $L G 7^{22}, L G 55^{174}, L G 2^{171}$ & AAAATAATCTCCACTTCACAAATTTTC & ATAAGTGCGTIATTAGTTTGGTCTTGT & * & * \\
\hline TA194 & 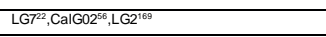 & TTTTTGGCTTATTAGACTGACTT & TIGCCATAAAATACAAAATCC & * & * \\
\hline TA22 & LG6 $6^{173}$ & TCTCCAACCCTTTAGATTGA & TCGTGTTTACTGAATGTGGA & & \\
\hline TA37 & $\mathrm{LG}^{170}, \mathrm{LG} 2^{174}, \mathrm{LG} 2^{175}$ & ACTTACATGAATTATCTTTCTTGGTCC & CGTATTCAAATAATCTTTCATCAGTCA & * & * \\
\hline TA39 & $\mathrm{LG}^{27^{22}}$ & TAAGCGTGGCTAACTTTATTTGC & ATAAATATCCAATTCTGGTAGTTGACG & * & \\
\hline TA64 & $L G 2, L G 1^{174}$ & ATATATCGTAACTCATTAATCATCCGC & AAATTGTTGTCATCAAATGGAAAATA & & \\
\hline TAA170 & 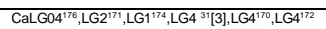 & TATAGAGTGAGAAGAAGCAAAGAGGAG & TATTTGCATCAATGTTCTGTAGTGTTT & * & \\
\hline TAA194 & 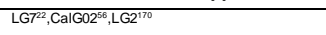 & AACGGTTATCTATAATTAATTGTGCAAG & AATCTTGTCAACCGCATTAATAATTT & & \\
\hline TR29 & $L G^{22}, L G 2^{169}$ & GCCCACTGAAAAATAAAAAG & ATTTGAACCTCAAGTTCTCG & * & * \\
\hline TR31 & $\mathrm{CalG03^{86 } , \mathrm { LG } 2 ^ { 1 7 4 } , \mathrm { LQ } 2 ^ { 1 6 , } , \mathrm { LG } 1 ^ { 1 7 5 }}$ & CTTAATCGCACATTTACTCTAAAATCA & ATCCATTAAAACACGGTACCTATAAT & * & * \\
\hline TR7 & 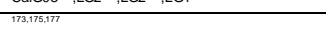 & GCATTATTCACCATTTGGAT & $\begin{array}{l}\text { TGTGATAATTTCTAAGTGTTTT } \\
\end{array}$ & * & * \\
\hline H1B09 & 178,799 & GGTTTCATGACCTGCACCTA & AAGAACCGAAAACACTTGTGA & * & * \\
\hline TA42 & $175,177,180$ & ATATCGAAATAAATAACAACAGGATGG & TAGTTGATACTTGGATGATAACCAAAA & * & * \\
\hline TA71 & $22,169,172,19$ & CGATTTAACACAAAACACAAA & CCTATCCATTGTCATCTCGT & * & * \\
\hline TAASH & $\frac{17}{17}$ & GGTAGACGCAAAAGAGTGGG & GCCACATTGACCAGGAATG & & * \\
\hline $\mathrm{H} 1 \mathrm{~B} 06$ & & GACTCACTCTCCAAATGGAACC & AAGCCCATGAAAACCATATATTC & * & * \\
\hline $\begin{array}{lll}\mathrm{H} 1 \mathrm{H} 13 \\
\text { TA179 }\end{array}$ & 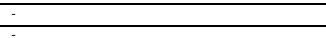 & TTCCTTTATCGCACCCTTCT & CCAGAGAAAGAGCAGCTACG & * & * \\
\hline
\end{tabular}

Table 2: Genomic distribution of SNPs and DArTs physically mapped on eight chickpea chromosomes.

\begin{tabular}{|l|l|l|l|l|}
\hline Chromosome & DArT marker count & DArT Density & SNP Density & SNP Marker count \\
\hline Ca1 & 374 & 19 & 26 & 333 \\
\hline Ca2 & 243 & 23 & 27 & 233 \\
\hline Ca3 & 277 & 25 & 31 & 236 \\
\hline Ca4 & 755 & 27 & 35 & 632 \\
\hline Ca5 & 290 & 33 & 35 & 244 \\
\hline Ca6 & 483 & 17 & 41 & 376 \\
\hline Ca7 & 413 & 49 & 48 & 305 \\
\hline Ca8 & 127 & 54 & 19 & 127 \\
\hline
\end{tabular}


Table 3: The most salinity tolerant genotypes obtained by analysis of variance (ANOVA) from the phenotypic readings of the green house and the field.

\begin{tabular}{|l|l|l|l|l|}
\hline Genotype & Field & Hydroponic & Origin & Province \\
\hline IG70782 & 2 & 2 & Pakistan & Punjab \\
\hline IG70430 & 2.5 & 2 & Pakistan & Punjab \\
\hline IG70764 & 2.5 & 2 & Pakistan & Sindh \\
\hline IG117703 & 2.5 & 2 & Pakistan & Punjab \\
\hline IG6057 & 2.5 & 2.5 & Pakistan & NWF \\
\hline IG8447 & 2.5 & 2.5 & Azrabejan & Lankaran \\
\hline IG70249 & 2.5 & 2.5 & Pakistan & Sindh \\
\hline
\end{tabular}

Table 4 The ANOVA output for differences between the green house and field phenotyping.

\begin{tabular}{|l|r|r|r|r|}
\hline Source of variation & \multicolumn{1}{|l|}{ d.f. } & \multicolumn{1}{l|}{ SS } & MS & \multicolumn{1}{l|}{ F } \\
\hline Genotype & 137 & 210.88 & 1.54 & $1.86^{* * *}$ \\
\hline Location & 1 & 1.04 & 1.04 & 1.26 \\
\hline Genotype X Location & 137 & 150.46 & 1.1 & 1.33 \\
\hline Error & 275 & 227.41 & 0.83 & \\
\hline Total & 551 & 609.38 & & \\
\hline
\end{tabular}

Table 5: The 16 polymorphic SSR markers used and their association to the salinity stress tolerance in the hydroponic experiment in the green house and Arish field environments.

\begin{tabular}{|l|l|l|l|l|}
\hline Marker & PIC & hydroponic & Arish field & ANOVA \\
\hline ICCM0178 & 0.5 & 1 & 0.7 & 0.4 \\
\hline TAA170 & 0.9 & 0.006 & 0.06 & 0.02 \\
\hline H1H13 & 0.3 & 0.6 & 0.8 & 0.8 \\
\hline H1B06 & 0.5 & 0.3 & 0.4 & 0.9 \\
\hline TA194 & 0.7 & 0.3 & 0.4 & 0.07 \\
\hline TA37 & 0.5 & 0.2 & 0.6 & 0.3 \\
\hline TA18 & 0.8 & 0.8 & 0.1 & 0.6 \\
\hline ICCM0293 & 0.7 & 0.9 & 0.4 & 0.9 \\
\hline TA42 & 0.8 & 0.2 & 0.4 & 0.6 \\
\hline TR31 & 0.6 & 0.5 & 0.9 & 0.4 \\
\hline TA179 & 0.7 & 1 & 0.4 & 0.9 \\
\hline TR29 & 0.8 & 0.52 & 0.2 & 0.2 \\
\hline TA71 & 0.7 & 0.2 & 0.4 & 0.1 \\
\hline TAASH & 0.6 & 0.4 & 0.7 & 0.5 \\
\hline H1B09 & 0.7 & 0.1 & 0.4 & 0.6 \\
\hline TR7 & 0.6 & 0.6 & 0.6 & 0.5 \\
\hline
\end{tabular}


Table 6: The SNPs, DArTs and SSR markers close genes and gene effect.

\begin{tabular}{|c|c|c|c|c|c|c|c|c|}
\hline Chromosome & Start & End & Gene name & SNP Name & Start & End & Effect & $\begin{array}{l}\text { Marker } \\
\text { Type }\end{array}$ \\
\hline Ca1 & 22102973 & 22103524 & NIPBL & SNP1268 & 3934547 & - & MODIFIER & SNP \\
\hline Ca1 & 6377188 & 6381838 & UN & SNP1451 & 22106206 & - & MODIFIER & SNP \\
\hline Ca1 & 6386498 & 6388905 & MAP-NDL & SNP1487 & 6383629 & - & MODIFIER & SNP \\
\hline Ca2 & 3920563 & 3935917 & P67 & SNP1487 & 6383629 & - & MODIFIER & SNP \\
\hline Ca3 & 39213565 & 39216469 & PUB9 & SNP1667 & 39215603 & - & MODIFIER & SNP \\
\hline Ca3 & 14517059 & 14520739 & TOMM6 & SNP190 & 14518700 & - & MODIFIER & SNP \\
\hline Ca3 & 23326348 & 23329856 & TT12 & SNP1947 & 23327600 & - & MODIFIER & SNP \\
\hline Ca3 & 23331054 & 23334408 & E3_ubiquitin_ligase & SNP1947 & 23327600 & - & MODIFIER & SNP \\
\hline $\mathrm{Ca} 4$ & 45624806 & 45631675 & APEX2 & SNP2021 & 14771678 & - & MODIFIER & SNP \\
\hline Ca4 & 16528933 & 16529810 & MED4 & SNP2021 & 14771678 & - & MODIFIER & SNP \\
\hline Ca4 & 16529838 & 16533251 & random_slug_p5 & SNP2095 & 13746772 & - & MODIFIER & SNP \\
\hline $\mathrm{Ca} 4$ & 16535273 & 16538805 & VPS39 & SNP2095 & 13746772 & - & MODIFIER & SNP \\
\hline Ca4 & 13717510 & 13717602 & kif11 & SNP2331 & 45628242 & - & MODIFIER & SNP \\
\hline Ca5 & 19845561 & 19857555 & UN & SNP948 & 16530812 & - & MODIFIER & SNP \\
\hline Ca7 & 14767114 & 14772777 & HBP-1b(c38) & SNP948 & 16530812 & - & MODIFIER & SNP \\
\hline Ca7 & 14774632 & 14777337 & CTL & SNP948 & 16530812 & - & MODIFIER & SNP \\
\hline Ca7 & 13738211 & 13742001 & HIS3 & DART2009 & 13717660 & - & UNKNOWN & DART \\
\hline Ca7 & 13749560 & 13759327 & $\mathrm{HIBCH}$ & DART769 & 19859119 & - & UNKNOWN & DART \\
\hline Ca1 & 8579323 & 8579615 & HYPK & GAA44 & 8579440 & 8579624 & UNKNOWN & SSR \\
\hline Ca1 & 8579323 & 8579615 & PBL & GAA44 & 8582087 & 8589091 & UNKNOWN & SSR \\
\hline Ca1 & 30480316 & 30480448 & UC & TA22 & 30481063 & 30484174 & UNKNOWN & SSR \\
\hline Ca1 & 30480316 & 30480448 & UC & TA22 & 30481197 & 30481421 & UNKNOWN & SSR \\
\hline Ca1 & 280162 & 280372 & EIF3C & TAA170 & 14148718 & 14153238 & UNKNOWN & SSR \\
\hline Ca1 & 280162 & 280372 & ASK10 & TAA170 & 14155412 & 14156240 & UNKNOWN & SSR \\
\hline Ca1 & 280162 & 280372 & CHSP70 & TAA170 & 267731 & 271187 & UNKNOWN & SSR \\
\hline Ca2 & 7517182 & 7518107 & USP17L2 & H1N12 & 46943791 & 46944124 & UNKNOWN & SSR \\
\hline Ca2 & 7517182 & 7518107 & UC & H1N12 & 7501062 & 7507760 & UNKNOWN & SSR \\
\hline Ca2 & 32200882 & 32201085 & Cucumisin-like & TA194 & 16817161 & 16817183 & UNKNOWN & SSR \\
\hline Ca2 & 17196291 & 17196573 & PERK9 & TA37 & 17186142 & 17192315 & UNKNOWN & SSR \\
\hline Ca3 & 12965840 & 12965951 & TFIID & H2J09 & 27319090 & 27322337 & UNKNOWN & SSR \\
\hline Ca3 & 16591364 & 16591641 & RPL32 & ICCM0178 & 16592795 & 16594742 & UNKNOWN & SSR \\
\hline Ca3 & 16591364 & 16591641 & OXI1 & ICCM0178 & 16585565 & 16588533 & UNKNOWN & SSR \\
\hline Ca3 & 16819768 & 16819858 & bHLH62 & TA194 & 45762276 & 45767196 & UNKNOWN & SSR \\
\hline Ca3 & 29597808 & 29598023 & DREB2F & TA64 & 29600041 & 29601190 & UNKNOWN & SSR \\
\hline Ca3 & 29597808 & 29598023 & SMUBP-2 & TA64 & 29601398 & 29608471 & UNKNOWN & SSR \\
\hline Ca3 & 29597808 & 29598023 & UC & TA64 & 29575704 & 29593101 & UNKNOWN & SSR \\
\hline Ca3 & 29597808 & 29598023 & UC & TA64 & 29592767 & 29592949 & UNKNOWN & SSR \\
\hline Ca3 & 3477462 & 3559535 & RPP1C & TAA194 & 3557121 & 3557498 & UNKNOWN & SSR \\
\hline Ca3 & 3477462 & 3559535 & UC & TAA194 & 3481336 & 3481777 & UNKNOWN & SSR \\
\hline $\mathrm{Ca} 4$ & 9102502 & 9102731 & DLAT & CaSTMS11 & 9102461 & 9102521 & UNKNOWN & SSR \\
\hline Ca4 & 9102502 & 9102731 & PK & CaSTMS11 & 9104818 & 9110326 & UNKNOWN & SSR \\
\hline Ca4 & 8913305 & 8914136 & CKI1 & ICCM0293 & 8912696 & 8913273 & UNKNOWN & SSR \\
\hline $\mathrm{Ca} 4$ & 8913305 & 8914136 & UC & ICCM0293 & 8917824 & 8920834 & UNKNOWN & SSR \\
\hline $\mathrm{Ca} 4$ & 14146314 & 14146529 & CRK25 & TAA170 & 273319 & 279318 & UNKNOWN & SSR \\
\hline Ca4 & 14146314 & 14146529 & PR & TAA170 & 14138672 & 14139743 & UNKNOWN & SSR \\
\hline $\mathrm{Ca} 4$ & 14146314 & 14146529 & SYP24 & TAA170 & 289201 & 293996 & UNKNOWN & SSR \\
\hline
\end{tabular}




\begin{tabular}{|l|r|r|l|l|r|r|l|l|}
\hline Ca5 & 35796257 & 35796416 & trc & CaSTMS22 & 35796138 & 35796280 & UNKNOWN & SSR \\
\hline Ca5 & 35796257 & 35796416 & SNRPA & CaSTMS22 & 35800401 & 35803070 & UNKNOWN & SSR \\
\hline Ca5 & 38745589 & 38745797 & ABHD17B & GA4 & 38745778 & 38746079 & UNKNOWN & SSR \\
\hline Ca5 & 38745589 & 38745797 & tipD & GA4 & 38736360 & 38740931 & UNKNOWN & SSR \\
\hline Ca5 & 27314665 & 27314754 & eff & H2J09 & 27310193 & 27310262 & UNKNOWN & SSR \\
\hline Ca5 & 27314665 & 27314754 & UC & H2J09 & 12972787 & 12980678 & UNKNOWN & SSR \\
\hline Ca5 & 9535702 & 9535872 & MOCS2 & H4F07 & 9535822 & 9537098 & UNKNOWN & SSR \\
\hline Ca5 & 9535702 & 9535872 & MAIL3 & H4F07 & 9540227 & 9540326 & UNKNOWN & SSR \\
\hline Ca5 & 23840621 & 23841280 & UC & TA18 & 23787120 & 23831853 & UNKNOWN & SSR \\
\hline Ca5 & 23840621 & 23841280 & UC & TA18 & 23831565 & 23831853 & UNKNOWN & SSR \\
\hline Ca5 & 10350148 & 10350439 & $2014-03-03$ & TA39 & 10344830 & 10346113 & UNKNOWN & SSR \\
\hline Ca5 & 10350148 & 10350439 & UC & TA39 & 10339812 & 10340291 & UNKNOWN & SSR \\
\hline Ca6 & 46936179 & 46937651 & AMPD & H1N12 & 7519343 & 7521986 & UNKNOWN & SSR \\
\hline Ca6 & 41372711 & 41373830 & $7 O M T$ & TA18 & 41381250 & 41381294 & UNKNOWN & SSR \\
\hline Ca7 & 37936821 & 37936997 & BON1 & CaSTMS25 & 37936934 & 37937074 & UNKNOWN & SSR \\
\hline Ca7 & 45756763 & 45757560 & rl5 & TA194 & 32201780 & 32202313 & UNKNOWN & SSR \\
\hline
\end{tabular}

Table 7: The SNPs and DArTs physical position and marker-trait association significance pvalue.

\begin{tabular}{|l|r|r|r|}
\hline Marker & \multicolumn{1}{|l|}{ Chr } & \multicolumn{1}{|l|}{ Position } & P-value \\
\hline DART2393 & 2 & 2770214 & 0.000855266 \\
\hline SNP2021 & 7 & 14771612 & 0.001071408 \\
\hline SNP1268 & 2 & 3934500 & 0.001626215 \\
\hline SNP1451 & 1 & 22106194 & 0.001700108 \\
\hline DART769 & 5 & 19859119 & 0.003068851 \\
\hline SNP1487 & 1 & 6383602 & 0.003249102 \\
\hline SNP1667 & 3 & 39215537 & 0.003949766 \\
\hline SNP2095 & 7 & 13746706 & 0.004381146 \\
\hline SNP190 & 3 & 14518694 & 0.004515574 \\
\hline SNP2247 & 2 & 33974127 & 0.005002969 \\
\hline SNP1947 & 3 & 23327546 & 0.005224952 \\
\hline DART2009 & 4 & 13717660 & 0.00557311 \\
\hline SNP2331 & 4 & 45628179 & 0.006951469 \\
\hline SNP948 & 4 & 16530791 & 0.008006447 \\
\hline
\end{tabular}


bioRxiv preprint doi: https://doi.org/10.1101/519744; this version posted January 13,2019 . The copyright holder for this preprint (which was not certified by peer review) is the author/funder. All rights reserved. No reuse allowed without permission.

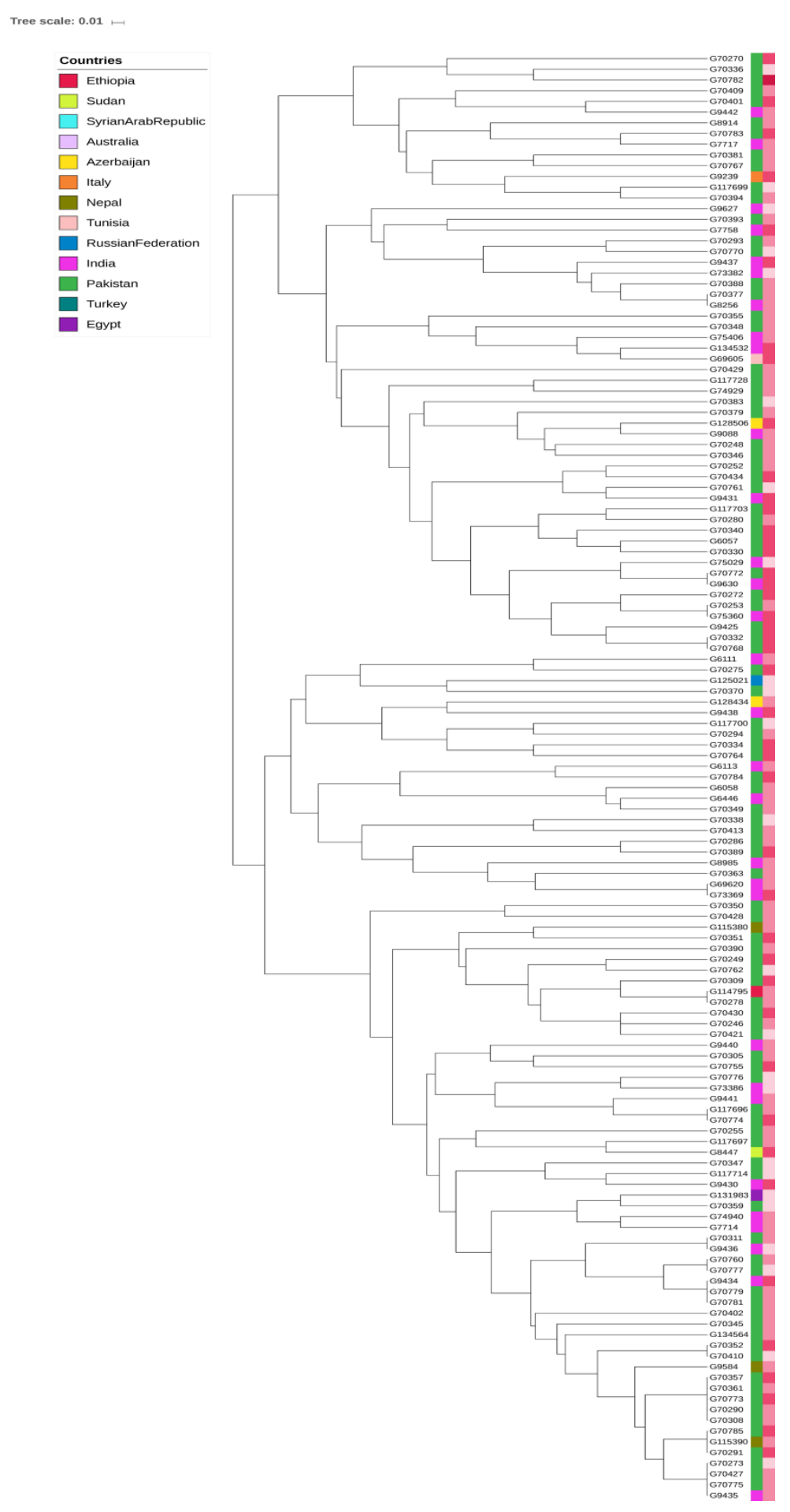

Figure 1 : The phyolegenetic tree of chickpea genotypes based on SSR markers. 
bioRxiv preprint doi: https://doi.org/10.1101/519744; this version posted January 13,2019 . The copyright holder for this preprint (which was not certified by peer review) is the author/funder. All rights reserved. No reuse allowed without permission.
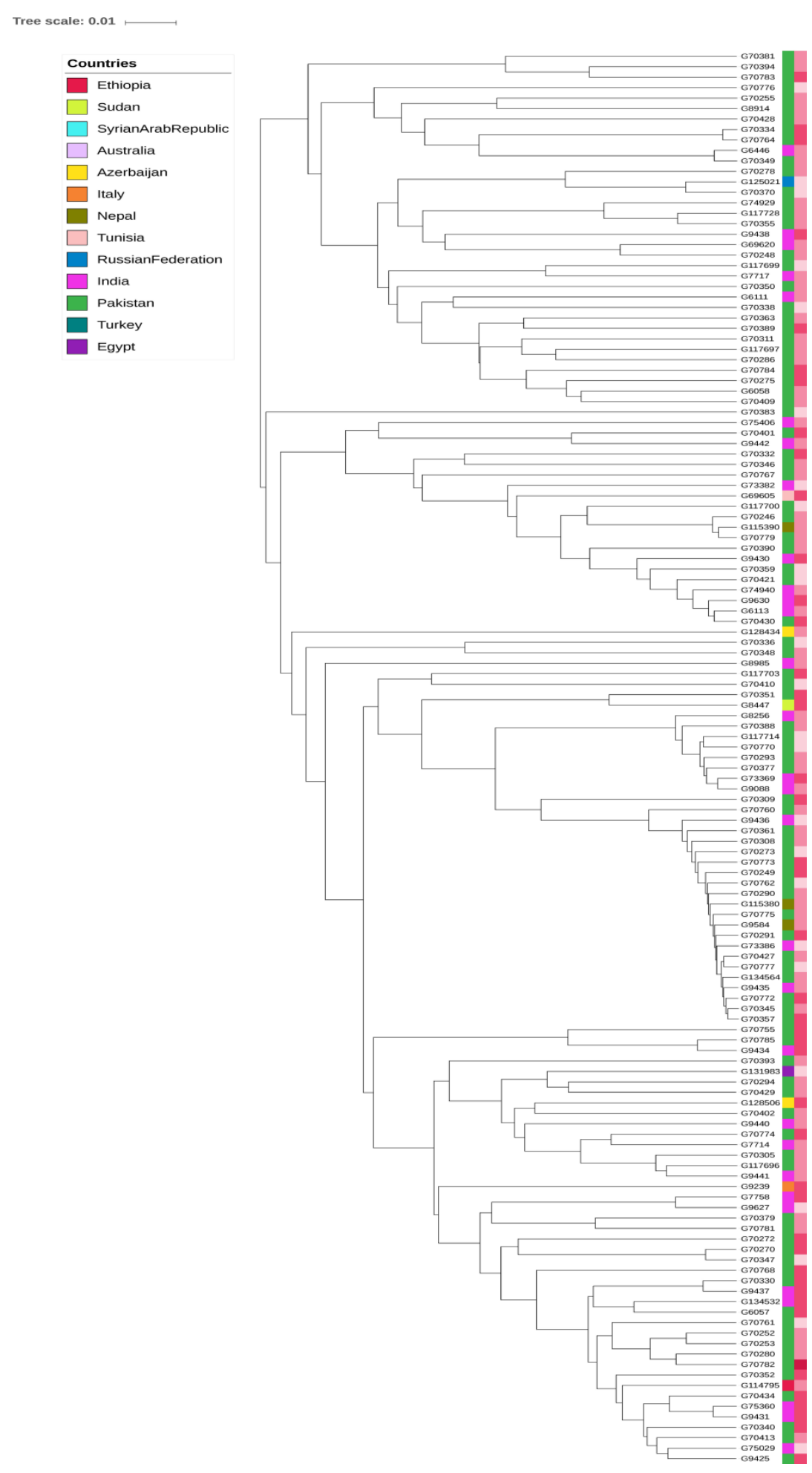

Figure 2: The phyolegenetic tree of chickpea genotypes based on DArT markers. 
bioRxiv preprint doi: https://doi.org/10.1101/519744; this version posted January 13,2019 . The copyright holder for this preprint (which was not certified by peer review) is the author/funder. All rights reserved. No reuse allowed without permission.

Tree scale: 0.01

\begin{tabular}{|c|c|}
\hline Co & untries \\
\hline & Ethiopia \\
\hline & Sudan \\
\hline & SyrianArabRepublic \\
\hline & Australia \\
\hline & Azerbaijan \\
\hline & Italy \\
\hline & Nepal \\
\hline & Tunisia \\
\hline & RussianFederation \\
\hline & India \\
\hline & Pakistan \\
\hline & Turkey \\
\hline & Egypt \\
\hline
\end{tabular}

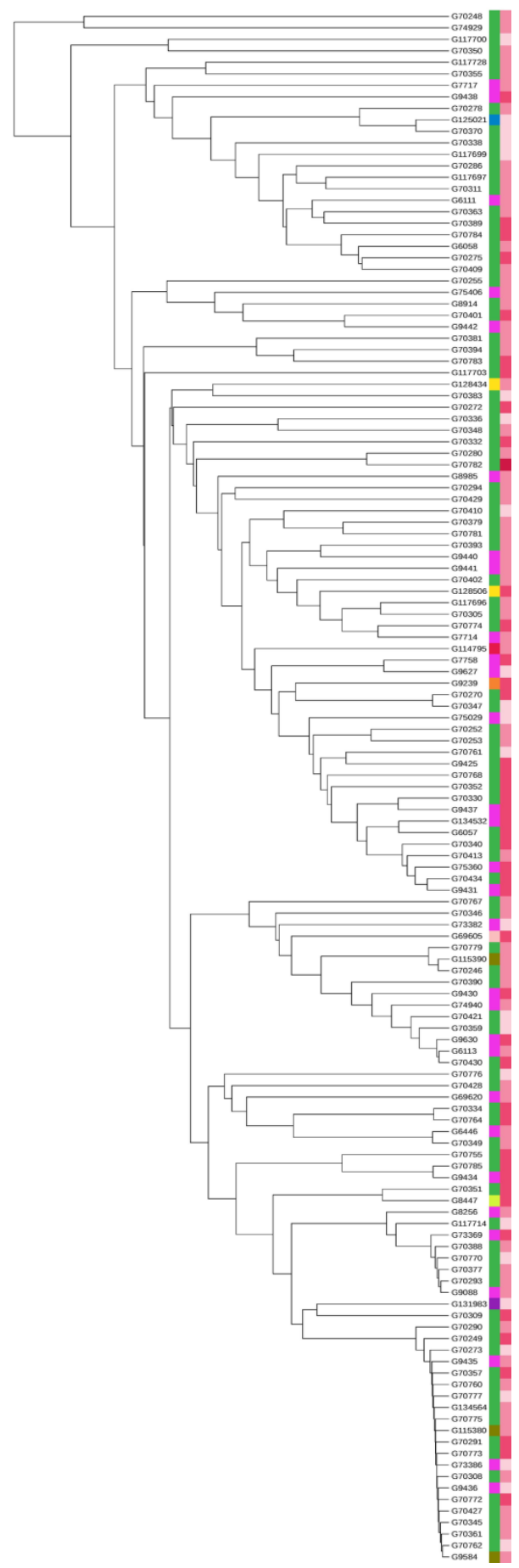

Figure 3 : The phyolegenetic tree of chickpea genotypes based on SNP markers. 


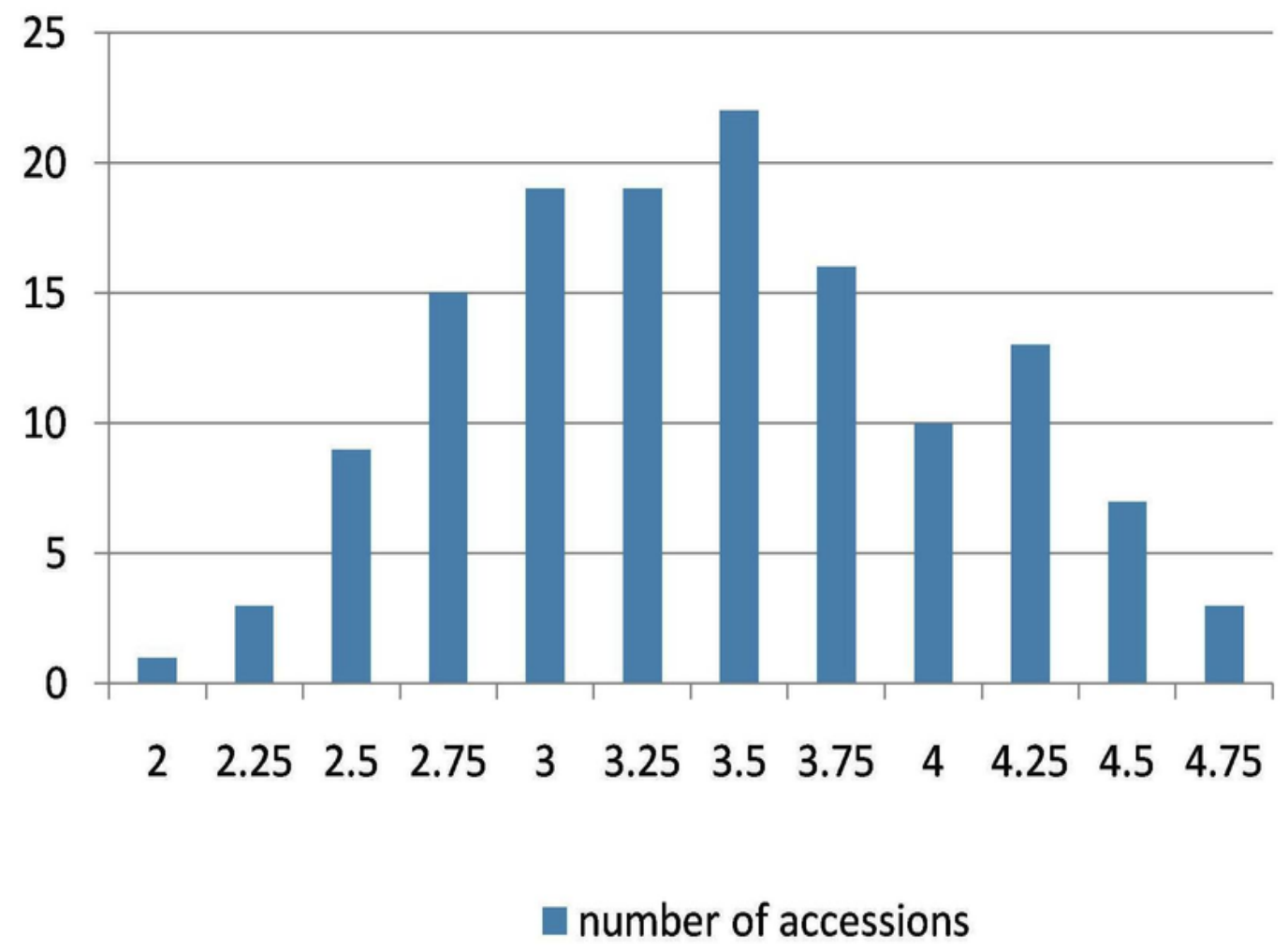

Figure 4 : The phenotypic distribution for salinity tolerance among chickpea genotypes. 


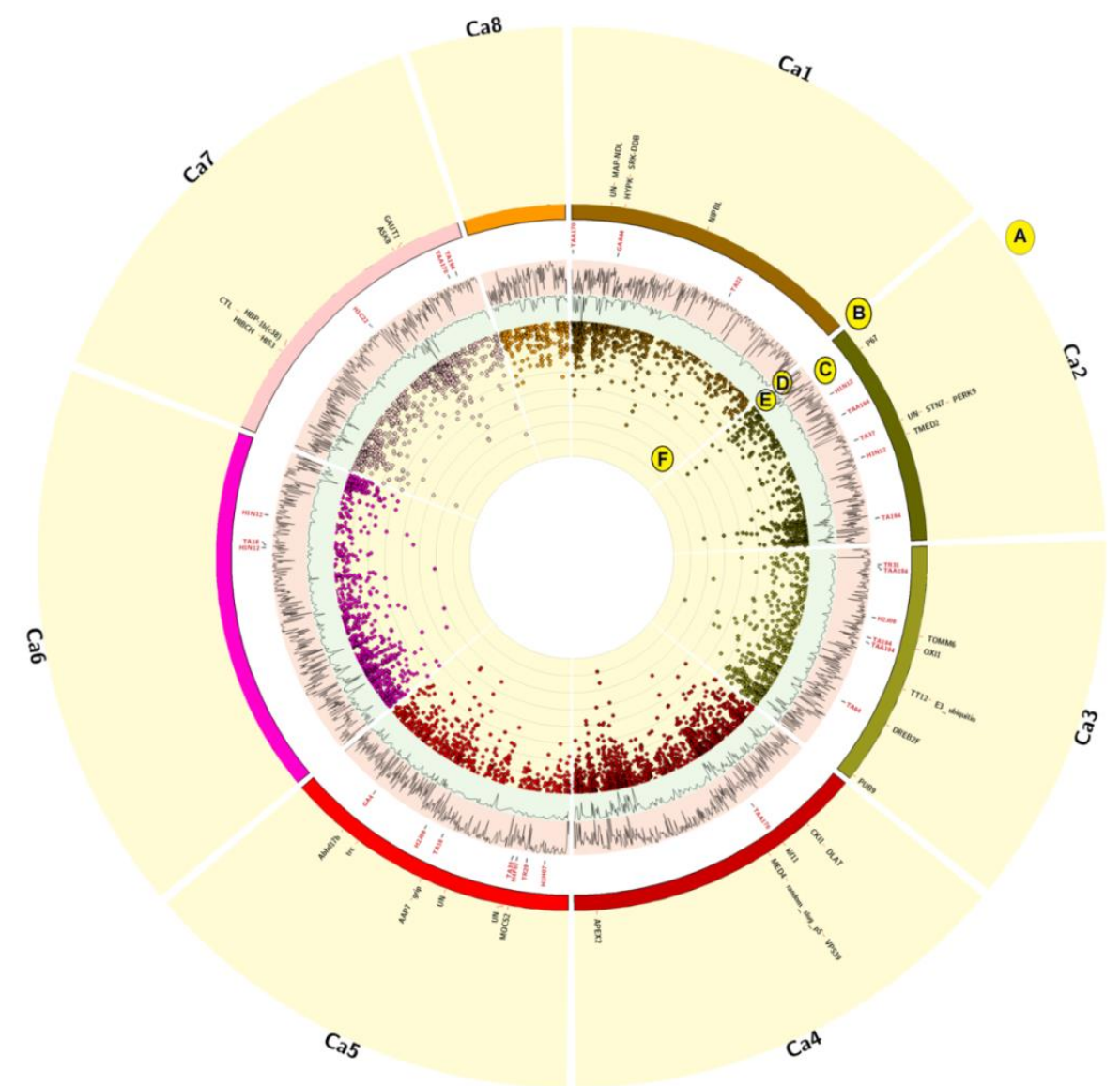

Figure 5 : Circos configuration depicting the distribution of genes (B) associated with SSR (C), SNP and DArT markers in addition to their P-value (-log10) scores, SNP markers density (E) and whole genome genes density (D). 


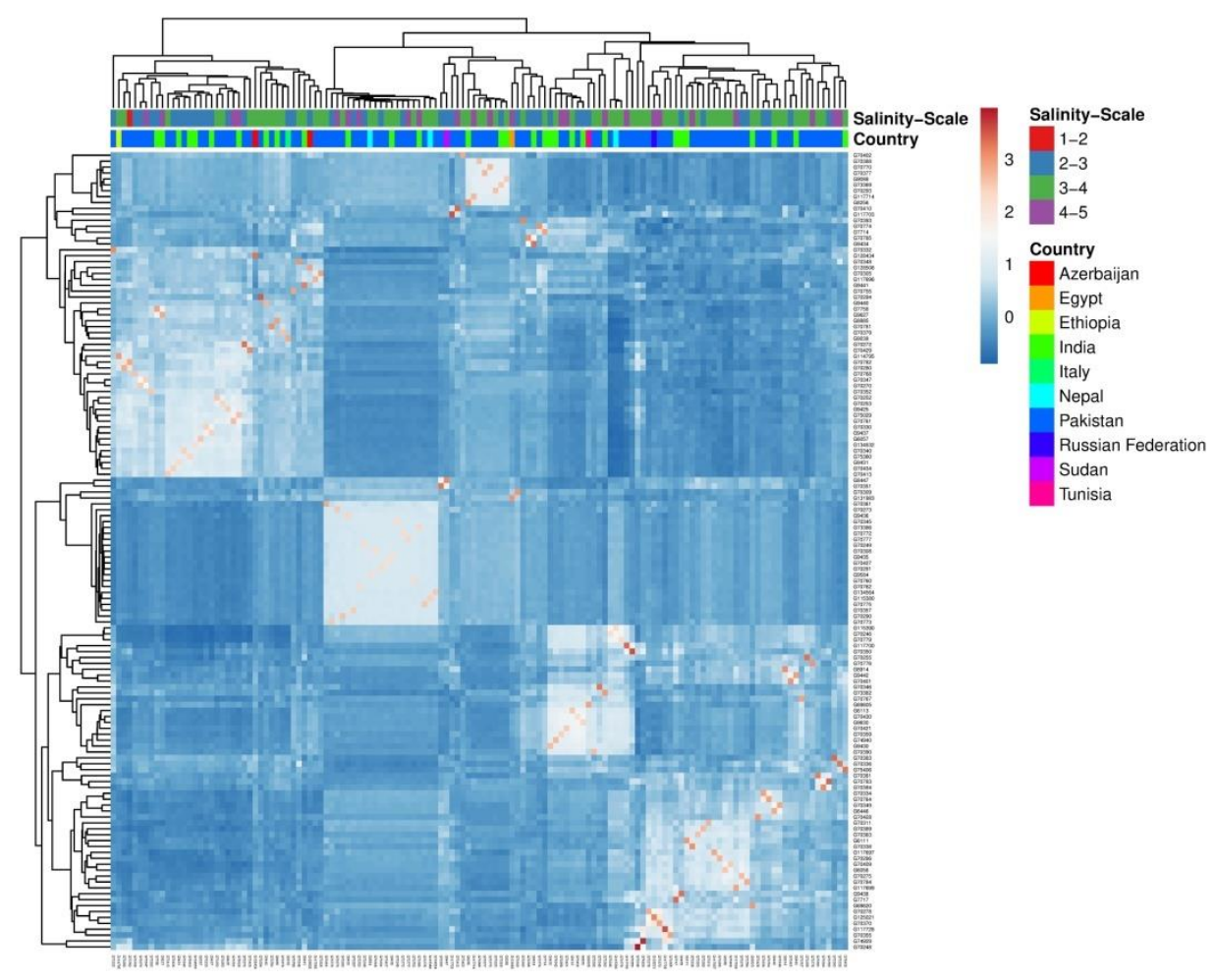

Figure 6 : The kinship analysis for chickpea genotypes based on SSR, SNP and DArT markers.

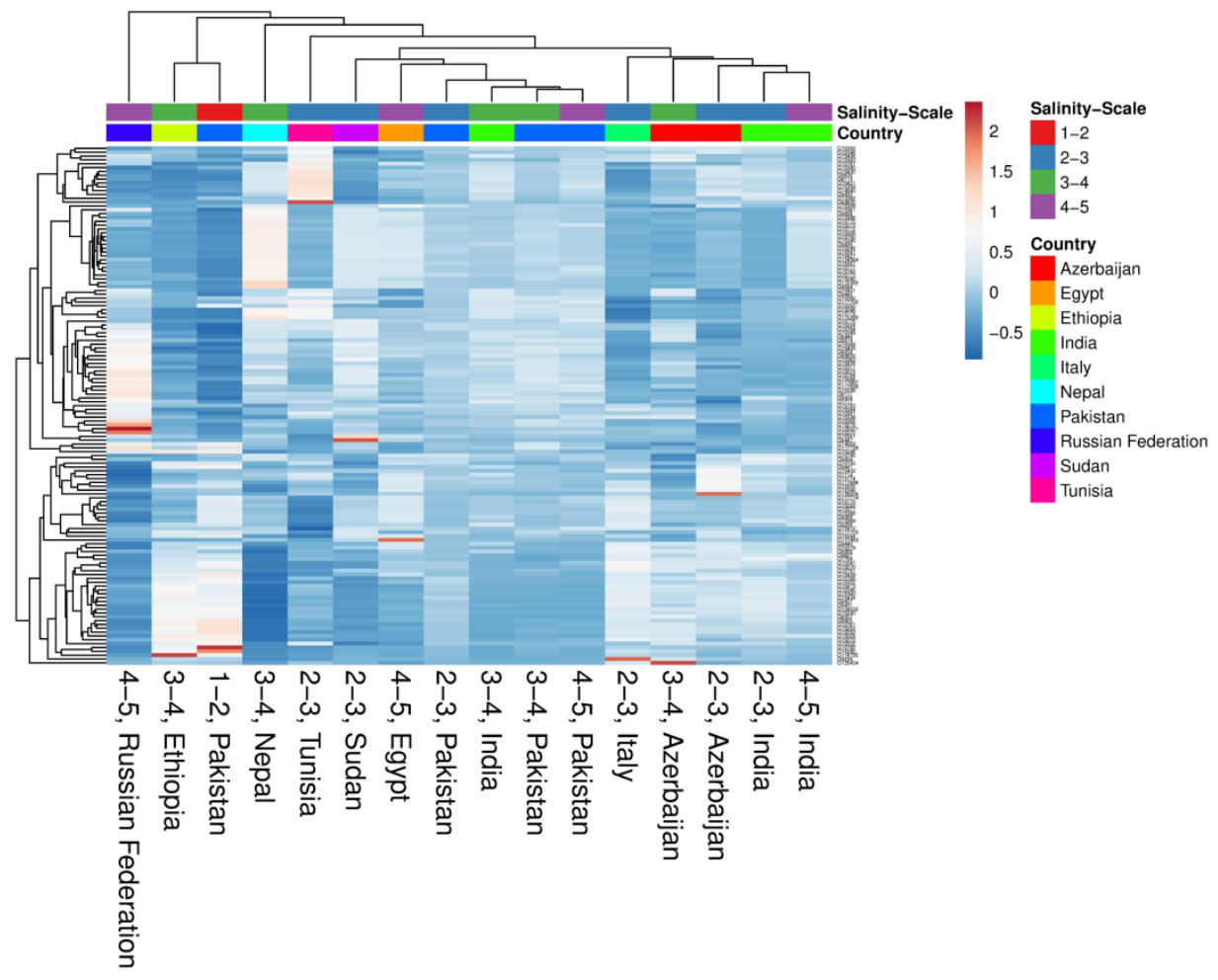

Figure 7 :The kinship analysis for chickpea genotypes after collapsing branches with the same similarity mean based on SSR, SNP and DArT markers. 
bioRxiv preprint doi: https://doi.org/10.1101/519744; this version posted January 13,2019 . The copyright holder for this preprint (which was not certified by peer review) is the author/funder. All rights reserved. No reuse allowed without permission.

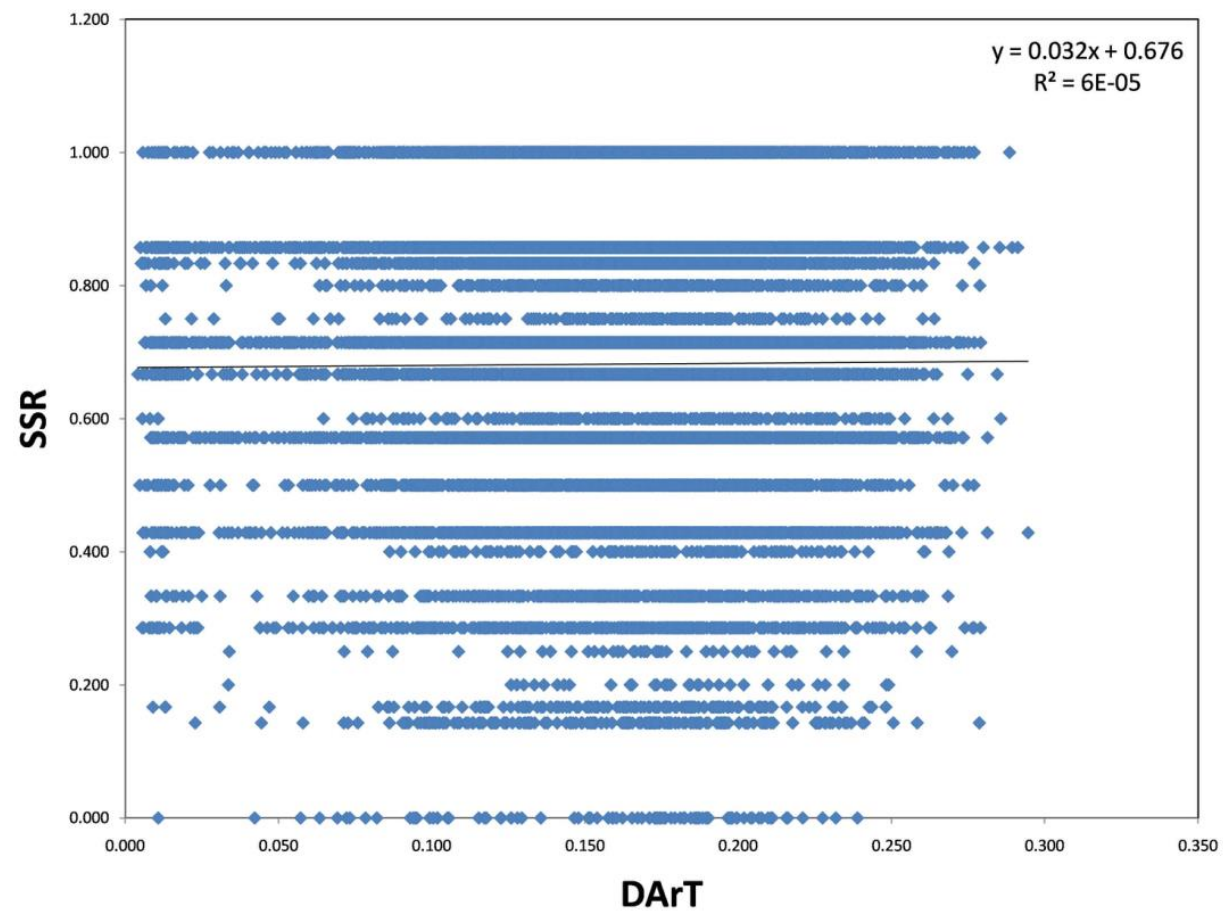

Figure 8 : The mantel correlation between SSR and DArT markers.

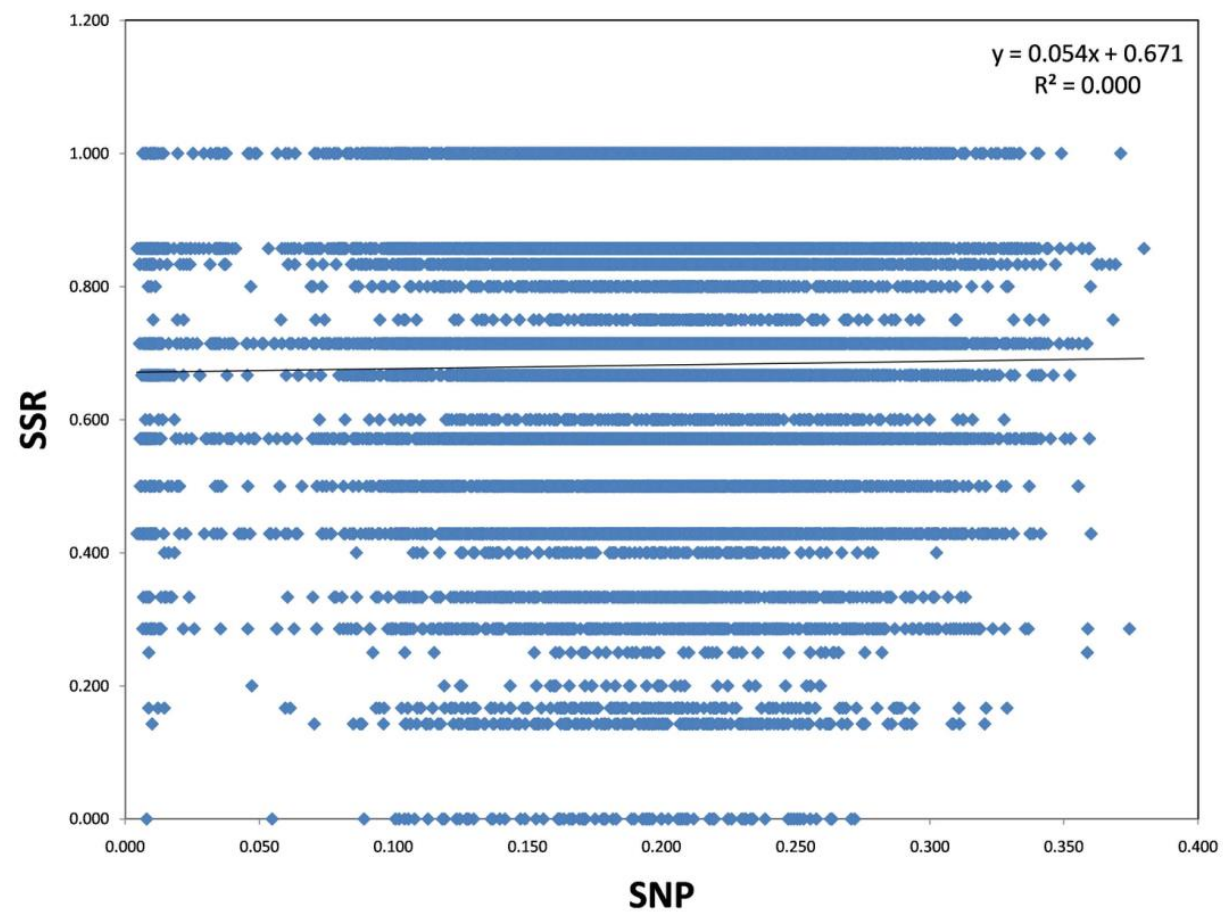

Figure 9 : The mantel correlation between SSR and SNP markers. 
bioRxiv preprint doi: https://doi.org/10.1101/519744; this version posted January 13,2019 . The copyright holder for this preprint (which was not certified by peer review) is the author/funder. All rights reserved. No reuse allowed without permission.

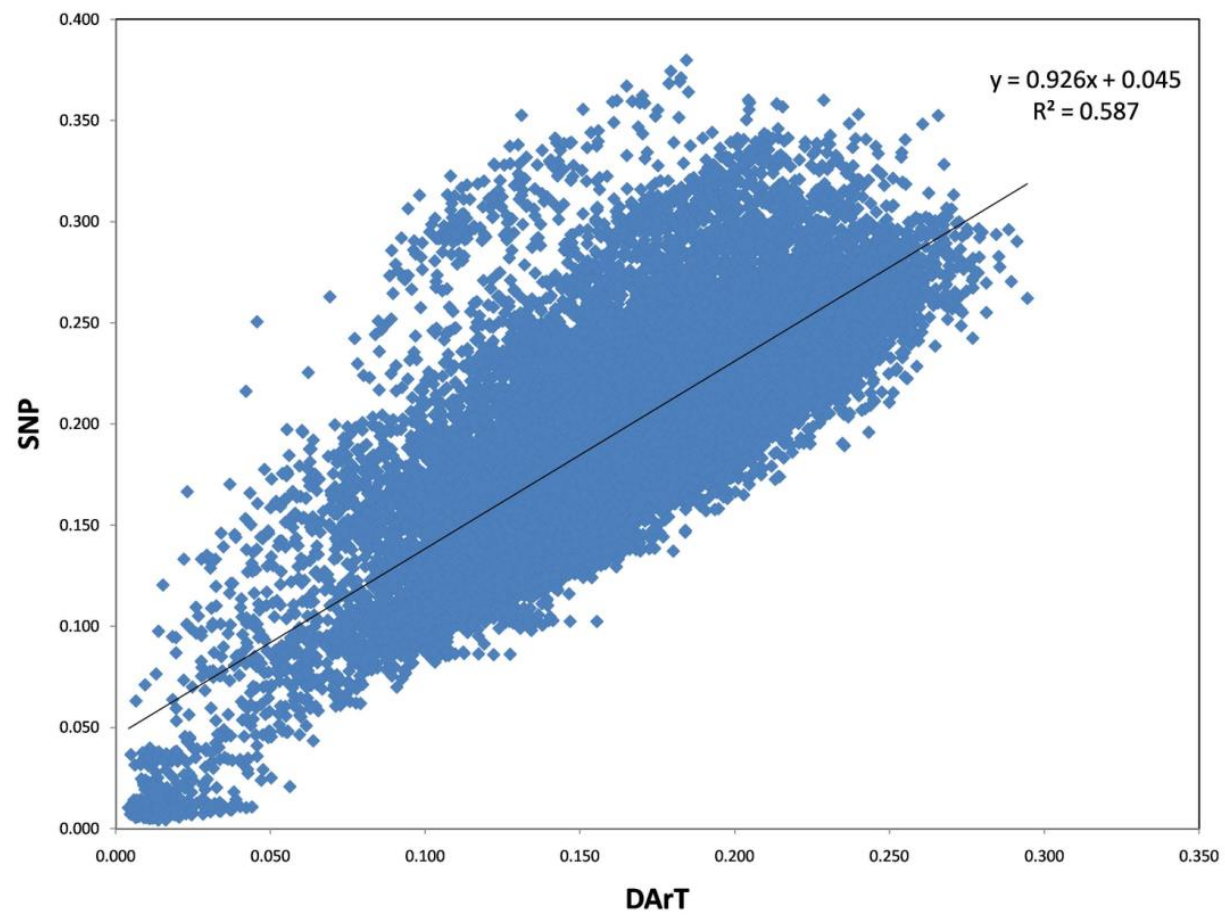

Figure 10 : The mantel correlation between DArT and SNP markers. 


\section{REFERENCES}

1. FAOSTAT. (2017).

2. Muehlbauer, F. J. \& Sarker, A. Economic Importance of Chickpea: Production, Value, and World Trade. in The Chickpea Genome 5-12 (Springer, 2017).

3. Shaheenuzzamn, M. Screening of chickpea genotypes against salinity stress. Bangladesh J. Agric. Res. 39, 605-619 (2014).

4. Parihar, P., Singh, S., Singh, R., Singh, V. P. \& Prasad, S. M. Effect of salinity stress on plants and its tolerance strategies: a review. Environ. Sci. Pollut. Res. 22, 4056-4075 (2015).

5. Khan, H. A., Siddique, K. H. M., Munir, R. \& Colmer, T. D. Salt sensitivity in chickpea: Growth, photosynthesis, seed yield components and tissue ion regulation in contrasting genotypes. J. Plant Physiol. 182, 1-12 (2015).

6. Flowers, T. J. et al. Salt sensitivity in chickpea. Plant. Cell Environ. 33, 490-509 (2010).

7. Zhu, J.-K. Regulation of ion homeostasis under salt stress. Curr. Opin. Plant Biol. 6, 441445 (2003).

8. Munns, R. \& Tester, M. Mechanisms of salinity tolerance. Annu. Rev. Plant Biol. 59, 651681 (2008).

9. Eyidogan, F. \& Öz, M. T. Effect of salinity on antioxidant responses of chickpea seedlings. Acta Physiol. Plant. 29, 485 (2007).

10. Kaashyap, M. et al. Differential regulation of genes involved in root morphogenesis and cell wall modification is associated with salinity tolerance in chickpea. Sci. Rep. 8, 4855 (2018).

11. Galvan-Ampudia, C. S. \& Testerink, C. Salt stress signals shape the plant root. Curr. Opin. Plant Biol. 14, 296-302 (2011).

12. Augustine, S. M. et al. Overexpression of EaDREB2 and pyramiding of EaDREB2 with the pea DNA helicase gene (PDH45) enhance drought and salinity tolerance in sugarcane (Saccharum spp. hybrid). Plant Cell Rep. 34, 247-263 (2015).

13. Oyiga, B. C. et al. Allelic variations and differential expressions detected at quantitative trait loci for salt stress tolerance in wheat. Plant. Cell Environ. 41, 919-935 (2018).

14. Frouin, J. et al. Tolerance to mild salinity stress in japonica rice: A genome-wide association mapping study highlights calcium signaling and metabolism genes. PLoS One 13, e0190964 (2018). 
15. Li, D. et al. GWAS Uncovers Differential Genetic Bases for Drought and Salt Tolerances in Sesame at the Germination Stage. Genes (Basel). 9, 87 (2018).

16. Lata, C. \& Prasad, M. Role of DREBs in regulation of abiotic stress responses in plants. $J$. Exp. Bot. 62, 4731-4748 (2011).

17. Genc, Y. et al. Sodium exclusion QTL associated with improved seedling growth in bread wheat under salinity stress. Theor. Appl. Genet. 121, 877-894 (2010).

18. Turki, N., Shehzad, T., Harrabi, M. \& Okuno, K. Detection of QTLs associated with salinity tolerance in durum wheat based on association analysis. Euphytica 201, 29-41 (2015).

19. Molla, K. A., Debnath, A. B., Ganie, S. A. \& Mondal, T. K. Identification and analysis of novel salt responsive candidate gene based SSRs (cgSSRs) from rice (Oryza sativa L.). BMC Plant Biol. 15, 122 (2015).

20. Aliyu, R., Adamu, A. K., Muazu, S., Alonge, S. O. \& Gregorio, G. B. Tagging and validation of SSR markers to salinity tolerance QTLs in rice (Oryza spp). in 2010 International Conference on Biology, Environment and Chemistry, IPCBEE, IACSIT press, Singapore 328-332 (2011).

21. Pushpavalli, R. et al. Two key genomic regions harbour QTLs for salinity tolerance in ICCV 2\$times\$ JG 11 derived chickpea (Cicer arietinum L.) recombinant inbred lines. BMC Plant Biol. 15, 124 (2015).

22. Vadez, V. et al. Assessment of ICCV 2\$ltimes\$ JG 62 chickpea progenies shows sensitivity of reproduction to salt stress and reveals QTL for seed yield and yield components. Mol. Breed. 30, 9-21 (2012).

23. Rafalski, A. Applications of single nucleotide polymorphisms in crop genetics. Curr. Opin. Plant Biol. 5, 94-100 (2002).

24. Kumar, V. et al. Genome-wide association mapping of salinity tolerance in rice (Oryza sativa). DNA Res. 22, 133-145 (2015).

25. Patil, G. et al. Genomic-assisted haplotype analysis and the development of highthroughput SNP markers for salinity tolerance in soybean. Sci. Rep. 6, 19199 (2016).

26. Hazzouri, K. M. et al. Mapping of HKT1; 5 Gene in Barley Using GWAS Approach and Its Implication in Salt Tolerance Mechanism. Front. Plant Sci. 9, 156 (2018).

27. Wan, H. et al. Genome-wide association study reveals the genetic architecture underlying salt tolerance-related traits in rapeseed (Brassica napus L.). Front. Plant Sci. 8, 593 (2017). 
28. Singh, V. K. et al. QTL-seq for rapid identification of candidate genes for 100-seed weight and root/total plant dry weight ratio under rainfed conditions in chickpea. Plant Biotechnol. J. 14, 2110-2119 (2016).

29. Iquebal, M. A. et al. Discovery of putative herbicide resistance genes and its regulatory network in chickpea using transcriptome sequencing. Front. Plant Sci. 8, 958 (2017).

30. Deokar, A., Sagi, M., Daba, K. \& Tar'an, B. QTL sequencing strategy to map genomic regions associated with resistance to ascochyta blight in chickpea. Plant Biotechnol. J. (2018).

31. Thudi, M. et al. Genomics-assisted breeding for drought tolerance in chickpea. Funct. Plant Biol. 41, 1178-1190 (2014).

32. Raman, H. et al. A consensus map of rapeseed (Brassica napus L.) based on diversity array technology markers: applications in genetic dissection of qualitative and quantitative traits. BMC Genomics 14, 277 (2013).

33. Alexander, L. M., Kirigwi, F. M., Fritz, A. K. \& Fellers, J. P. Mapping and quantitative trait loci analysis of drought tolerance in a spring wheat population using amplified fragment length polymorphism and diversity array technology markers. Crop Sci. 52, 253-261 (2012).

34. Varshney, R. K. et al. Genome wide association analyses for drought tolerance related traits in barley (Hordeum vulgare L.). F. Crop. Res. 126, 171-180 (2012).

35. Fan, Y. et al. Genome-wide association study reveals a new QTL for salinity tolerance in Barley (Hordeum vulgare L.). Front. Plant Sci. 7, 946 (2016).

36. Sohail, Q. et al. Development of diversity array technology (DArT) markers for assessment of population structure and diversity in Aegilops tauschii. Breed. Sci. 62, 3845 (2012).

37. Golldack, D., Li, C., Mohan, H. \& Probst, N. Tolerance to drought and salt stress in plants: unraveling the signaling networks. Front. Plant Sci. 5, 151 (2014).

38. Fan, Y., Shabala, S., Ma, Y., Xu, R. \& Zhou, M. Using QTL mapping to investigate the relationships between abiotic stress tolerance (drought and salinity) and agronomic and physiological traits. BMC Genomics 16, 43 (2015).

39. Abdelraheem, A., Fang, D. D. \& Zhang, J. Quantitative trait locus mapping of drought and salt tolerance in an introgressed recombinant inbred line population of Upland cotton under the greenhouse and field conditions. Euphytica 214, 8 (2018).

40. Garg, R. et al. Transcriptome analyses reveal genotype-and developmental stage-specific molecular responses to drought and salinity stresses in chickpea. Sci. Rep. 6, 19228 
(2016).

41. Ahmed, I. M., Nadira, U. A., Bibi, N., Zhang, G. \& Wu, F. Tolerance to combined stress of drought and salinity in barley. in Combined Stresses in Plants 93-121 (Springer, 2015).

42. Jha, U. C. et al. Abiotic stresses, constraints and improvement strategies in chickpea. Plant Breed. 133, 163-178 (2014).

43. Khazaei, H., Street, K., Bari, A., Mackay, M. \& Stoddard, F. L. The FIGS (Focused Identification of Germplasm Strategy) approach identifies traits related to drought adaptation in Vicia faba genetic resources. PLoS One 8, e63107 (2013).

44. Mackay, M. C. \& others. Strategic planning for effective evaluation of plant germplasm. in Wheat genetic resources: meeting diverse needs. 21-348 (1990).

45. Mackay, M. C. One core collection or many. Core Collect. plant Genet. Resour. 199-210 (1995).

46. Mackay, M. C. et al. Focused identification of germplasm strategy--FIGS. Proc. 11th Wheat Breed. Assem. 20-24 (2004).

47. Bari, A. et al. Focused identification of germplasm strategy (FIGS) detects wheat stem rust resistance linked to environmental variables. Genet. Resour. Crop Evol. 59, 14651481 (2012).

48. Bari, A. et al. Predicting resistance to stripe (yellow) rust (Puccinia striiformis) in wheat genetic resources using focused identification of germplasm strategy. J. Agric. Sci. 152, 906-916 (2014).

49. Emebiri, L. C. et al. QTL mapping identifies a major locus for resistance in wheat to Sunn pest (Eurygaster integriceps) feeding at the vegetative growth stage. Theor. Appl. Genet. 130, 309-318 (2017).

50. Rogers, S. O. \& Bendich, A. J. Extraction of DNA from plant tissues. in Plant molecular biology manual 73-83 (Springer, 1989).

51. Altschul, S. F. et al. Gapped BLAST and PSI-BLAST: a new generation of protein database search programs. Nucleic Acids Res. 25, 3389-3402 (1997).

52. Nei, M. Analysis of gene diversity in subdivided populations. Proc. Natl. Acad. Sci. 70, 3321-3323 (1973).

53. Liu, K. \& Muse, S. V. PowerMarker: an integrated analysis environment for genetic marker analysis. Bioinformatics 21, 2128-2129 (2005).

54. Lipka, A. E. et al. GAPIT: genome association and prediction integrated tool. Bioinformatics 28, 2397-2399 (2012). 
55. Cingolani, P. et al. A program for annotating and predicting the effects of single nucleotide polymorphisms, SnpEff: SNPs in the genome of Drosophila melanogaster strain w1118; iso-2; iso-3. Fly (Austin). 6, 80-92 (2012).

56. Varshney, R. K. et al. Draft genome sequence of chickpea (Cicer arietinum) provides a resource for trait improvement. Nat. Biotechnol. 31, 240 (2013).

57. Ogata, H. et al. KEGG: Kyoto encyclopedia of genes and genomes. Nucleic Acids Res. 27, 29-34 (1999).

58. Kanehisa, M., Sato, Y. \& Morishima, K. BlastKOALA and GhostKOALA: KEGG tools for functional characterization of genome and metagenome sequences. J. Mol. Biol. 428, 726-731 (2016).

59. Krzywinski, M. et al. Circos: an information aesthetic for comparative genomics. Genome Res. 19, 1639-1645 (2009).

60. Letunic, I. \& Bork, P. Interactive Tree Of Life (iTOL): an online tool for phylogenetic tree display and annotation. Bioinformatics 23, 127-128 (2006).

61. Metsalu, T. \& Vilo, J. ClustVis: a web tool for visualizing clustering of multivariate data using Principal Component Analysis and heatmap. Nucleic Acids Res. 43, W566--W570 (2015).

62. Van Inghelandt, D., Melchinger, A. E., Lebreton, C. \& Stich, B. Population structure and genetic diversity in a commercial maize breeding program assessed with SSR and SNP markers. Theor. Appl. Genet. 120, 1289-1299 (2010).

63. Elakhdar, A., EL-Sattar, M. A., Amer, K., Rady, A. \& Kumamaru, T. Population structure and marker--trait association of salt tolerance in barley (Hordeum vulgare L.). C. R. Biol. 339, 454-461 (2016).

64. Botstein, D., White, R. L., Skolnick, M. \& Davis, R. W. Construction of a genetic linkage map in man using restriction fragment length polymorphisms. Am. J. Hum. Genet. 32, 314 (1980).

65. Schuler, G. D. Sequence mapping by electronic PCR. Genome Res. 7, 541-550 (1997).

66. Lexa, M., Horak, J. \& Brzobohaty, B. Virtual PCR. 17, 192-193 (2001).

67. Russell, G. C. \& Guest, J. R. Sequence similarities within the family of dihydrolipoamide acyltransferases and discovery of a previously unidentified fungal enzyme. Biochim. Biophys. Acta (BBA)-Protein Struct. Mol. Enzymol. 1076, 225-232 (1991).

68. Taylor, N. L., Day, D. A. \& Millar, A. H. Environmental stress causes oxidative damage to plant mitochondria leading to inhibition of glycine decarboxylase. J. Biol. Chem. 277, 
$42663-42668$ (2002).

69. Rapala-Kozik, M., Wolak, N., Kujda, M. \& Banas, A. K. The upregulation of thiamine (vitamin B 1) biosynthesis in Arabidopsis thaliana seedlings under salt and osmotic stress conditions is mediated by abscisic acid at the early stages of this stress response. BMC Plant Biol. 12, 2 (2012).

70. Läuchli, A. \& Grattan, S. R. Plant growth and development under salinity stress. in Advances in molecular breeding toward drought and salt tolerant crops 1-32 (Springer, 2007).

71. Tavares, R., Vidal, J., Van Lammeren, A. \& Kreis, M. AtSK\$ $\$$, a plant homologue of SGG/GSK-3 marks developing tissues in Arabidopsis thaliana. Plant Mol. Biol. 50, 261271 (2002).

72. Li, J. \& Nam, K. H. Regulation of brassinosteroid signaling by a GSK3/SHAGGY-like kinase. Science (80-. ). 295, 1299-1301 (2002).

73. Saidi, Y., Hearn, T. J. \& Coates, J. C. Function and evolution of 'green'GSK3/Shaggylike kinases. Trends Plant Sci. 17, 39-46 (2012).

74. Piao, H. L., Lim, J. H., Kim, S. J., Cheong, G.-W. \& Hwang, I. Constitutive overexpression of AtGSK1 induces $\mathrm{NaCl}$ stress responses in the absence of $\mathrm{NaCl}$ stress and results in enhanced $\mathrm{NaCl}$ tolerance in Arabidopsis. Plant J. 27, 305-314 (2001).

75. Sterling, J. D. et al. Functional identification of an Arabidopsis pectin biosynthetic homogalacturonan galacturonosyltransferase. Proc. Natl. Acad. Sci. 103, 5236-5241 (2006).

76. Liu, J., Luo, M., Yan, X., Yu, C. \& Li, S. Characterization of genes coding for galacturonosyltransferase-like (GATL) proteins in rice. Genes Genomics 38, 917-929 (2016).

77. Atmodjo, M. A. et al. Galacturonosyltransferase (GAUT) 1 and GAUT7 are the core of a plant cell wall pectin biosynthetic homogalacturonan: galacturonosyltransferase complex. Proc. Natl. Acad. Sci. 108, 20225-20230 (2011).

78. Leimkühler, S. et al. Ten novel mutations in the molybdenum cofactor genes MOCS1 and MOCS2 and in vitro characterization of a MOCS2 mutation that abolishes the binding ability of molybdopterin synthase. Hum. Genet. 117, 565-570 (2005).

79. Mendel, R. R. \& Leimkühler, S. The biosynthesis of the molybdenum cofactors. JBIC J. Biol. Inorg. Chem. 20, 337-347 (2015).

80. Presta, L., Fondi, M., Emiliani, G. \& Fani, R. Molybdenum Cofactor-Containing Enzymes and Pathways. in Molybdenum Cofactors and Their role in the Evolution of Metabolic 
Pathways 33-52 (Springer, 2015).

81. Daniels, J. N., Wuebbens, M. M., Rajagopalan, K. V \& Schindelin, H. Crystal structure of a molybdopterin synthase- precursor $\mathrm{Z}$ complex: Insight into its sulfur transfer mechanism and its role in molybdenum cofactor deficiency. Biochemistry 47, 615-626 (2008).

82. Rentel, M. C. et al. OXI1 kinase is necessary for oxidative burst-mediated signalling in Arabidopsis. Nature 427, 858 (2004).

83. Petersen, L. N., Ingle, R. A., Knight, M. R. \& Denby, K. J. OXI1 protein kinase is required for plant immunity against Pseudomonas syringae in Arabidopsis. J. Exp. Bot. 60, 3727-3735 (2009).

84. Shumbe, L. et al. Singlet oxygen-induced cell death in Arabidopsis under high light stress is controlled by OXI1 kinase. Plant Physiol. pp--01546 (2016).

85. Camehl, I. et al. The OXI1 kinase pathway mediates Piriformospora indica-induced growth promotion in Arabidopsis. PLoS Pathog. 7, e1002051 (2011).

86. Deng, Y. et al. Arabidopsis histidine kinase CKI1 acts upstream of histidine phosphotransfer proteins to regulate female gametophyte development and vegetative growth. Plant Cell 22, 1232-1248 (2010).

87. Hejátko, J., Pernisova, M., Eneva, T., Palme, K. \& Brzobohat'yy, B. The putative sensor histidine kinase CKI1 is involved in female gametophyte development in Arabidopsis. Mol. Genet. genomics 269, 443-453 (2003).

88. Pekárová, B. et al. Structure and binding specificity of the receiver domain of sensor histidine kinase CKI1 from Arabidopsis thaliana. Plant J. 67, 827-839 (2011).

89. Tran, L.-S. P. et al. Functional analysis of AHK1/ATHK1 and cytokinin receptor histidine kinases in response to abscisic acid, drought, and salt stress in Arabidopsis. Proc. Natl. Acad. Sci. 104, 20623-20628 (2007).

90. Hwang, Y., Lee, H., Lee, Y.-S. \& Cho, H.-T. Cell wall-associated ROOT HAIR SPECIFIC 10, a proline-rich receptor-like kinase, is a negative modulator of Arabidopsis root hair growth. J. Exp. Bot. 67, 2007-2022 (2016).

91. Cho, H.-T. Arabinogalactan protein motif-containing receptor-like kinases are likely to play the negative feedback factor to maintain proper root hair length. Plant Signal. Behav. 11, 2007-2022 (2016).

92. Osakabe, Y., Osakabe, K., Shinozaki, K. \& Tran, L.-S. P. Response of plants to water stress. Front. Plant Sci. 5, 86 (2014).

93. Nakashima, K. et al. Organization and expression of two Arabidopsis DREB2 genes 
encoding DRE-binding proteins involved in dehydration-and high-salinity-responsive gene expression. Plant Mol. Biol. 42, 657-665 (2000).

94. Eftekhari, A., Baghizadeh, A., Yaghoobi, M. M. \& Abdolshahi, R. Differences in the drought stress response of DREB2 and CAT1 genes and evaluation of related physiological parameters in some bread wheat cultivars. Biotechnol. Biotechnol. Equip. 31, 709-716 (2017).

95. Cheng, L. et al. Overexpression of NnDREB2, isolated from lotus improves salt tolerance in transgenic Arabidopsis thaliana. Acta Physiol. Plant. 37, 261 (2015).

96. Matsukura, S. et al. Comprehensive analysis of rice DREB2-type genes that encode transcription factors involved in the expression of abiotic stress-responsive genes. Mol. Genet. Genomics 283, 185-196 (2010).

97. Willig, A., Shapiguzov, A., Goldschmidt-Clermont, M. \& Rochaix, J.-D. The phosphorylation status of the chloroplast protein kinase STN7 of Arabidopsis thaliana affects its turnover. Plant Physiol. pp--111 (2011).

98. Suzuki, N., Koussevitzky, S., Mittler, R. O. N. \& Miller, G. A. D. ROS and redox signalling in the response of plants to abiotic stress. Plant. Cell Environ. 35, 259-270 (2012).

99. Tikkanen, M., Gollan, P., Suorsa, M., Kangasjarvi, S. \& Aro, E.-M. STN7 operates in retrograde signaling through controlling redox balance in the electron transfer chain. Front. Plant Sci. 3, 277 (2012).

100. Strating, J. R. P. M. \& Martens, G. J. M. The p24 family and selective transport processes at the ER-Golgi interface. Biol. Cell 101, 495-509 (2009).

101. Doyle, S. L. et al. The GOLD domain-containing protein TMED7 inhibits TLR4 signalling from the endosome upon LPS stimulation. Nat. Commun. 3, 707 (2012).

102. Nishizawa, A. et al. Arabidopsis heat shock transcription factor A2 as a key regulator in response to several types of environmental stress. Plant J. 48, 535-547 (2006).

103. Tanaka, H. et al. Abiotic stress-inducible receptor-like kinases negatively control ABA signaling in Arabidopsis. Plant J. 70, 599-613 (2012).

104. Chern, M. et al. Correction: A Genetic Screen Identifies a Requirement for Cysteine-RichReceptor-Like Kinases in Rice NH1 (OsNPR1)-Mediated Immunity. PLoS Genet. 12, e1006182 (2016).

105. Yeh, Y.-H., Chang, Y.-H., Huang, P.-Y., Huang, J.-B. \& Zimmerli, L. Enhanced Arabidopsis pattern-triggered immunity by overexpression of cysteine-rich receptor-like kinases. Front. Plant Sci. 6, 322 (2015). 
106. Idänheimo, N. et al. The Arabidopsis thaliana cysteine-rich receptor-like kinases CRK6 and CRK7 protect against apoplastic oxidative stress. Biochem. Biophys. Res. Commun. 445, 457-462 (2014).

107. Sun, X.-L. et al. GsSRK, a G-type lectin S-receptor-like serine/threonine protein kinase, is a positive regulator of plant tolerance to salt stress. J. Plant Physiol. 170, 505-515 (2013).

108. Simko, I., Eujayl, I. \& van Hintum, T. J. L. Empirical evaluation of DArT, SNP, and SSR marker-systems for genotyping, clustering, and assigning sugar beet hybrid varieties into populations. Plant Sci. 184, 54-62 (2012).

109. Hardy, O. J. Estimation of pairwise relatedness between individuals and characterization of isolation-by-distance processes using dominant genetic markers. Mol. Ecol. 12, 15771588 (2003).

110. Cappa, E. P., Klápště, J., Garcia, M. N., Villalba, P. V \& Poltri, S. N. M. SSRs, SNPs and DArTs comparison on estimation of relatedness and genetic parameters' precision from a small half-sib sample population of Eucalyptus grandis. Mol. Breed. 36, 97 (2016).

111. Ma, Y. et al. Quantitative trait loci for salinity tolerance identified under drained and waterlogged conditions and their association with flowering time in barley (Hordeum vulgare. L). PLoS One 10, e0134822 (2015).

112. Gill, M. B. et al. Cell-based phenotyping reveals QTL for membrane potential maintenance associated with hypoxia and salinity stress tolerance in barley. Front. Plant Sci. 8, 1941 (2017).

113. Ghaedrahmati, M. et al. Mapping QTLs associated with salt tolerance related traits in wheat (Triticum aestivum L.). J. Agric. Sci. Technol. 16, 1413-1428 (2014).

114. Zhang, Z. et al. Mixed linear model approach adapted for genome-wide association studies. Nat. Genet. 42, 355 (2010).

115. Glynn, S. E. et al. Structure and mechanism of imidazoleglycerol-phosphate dehydratase. Structure 13, 1809-1817 (2005).

116. Hawes, J. W. et al. Primary structure and tissue-specific expression of human $\$ \beta \$$ hydroxyisobutyryl-coenzyme A hydrolase. J. Biol. Chem. 271, 26430-26434 (1996).

117. Liang, Y. et al. Identification and computational annotation of genes differentially expressed in pulp development of Cocos nucifera L. by suppression subtractive hybridization. BMC Plant Biol. 14, 205 (2014).

118. Ding, H. et al. Isolation and characterization of drought-responsive genes from peanut roots by suppression subtractive hybridization. Electron. J. Biotechnol. 17, 304-310 (2014). 
119. Wang, W. \& Chen, X. HUA ENHANCER3 reveals a role for a cyclin-dependent protein kinase in the specification of floral organ identity in Arabidopsis. Development 131, 3147-3156 (2004).

120. Bermudez, V. P. et al. In vitro loading of human cohesin on DNA by the human Scc2Scc4 loader complex. Proc. Natl. Acad. Sci. 109, 9366-9371 (2012).

121. Rhodes, J., Mazza, D., Nasmyth, K. \& Uphoff, S. Scc2/Nipbl hops between chromosomal cohesin rings after loading. Elife 6, e30000 (2017).

122. Khatri, N. \& Mudgil, Y. Hypothesis: NDL proteins function in stress responses by regulating microtubule organization. Front. Plant Sci. 6, 947 (2015).

123. Goodson, H. V \& Jonasson, E. M. Microtubules and microtubule-associated proteins. Cold Spring Harb. Perspect. Biol. 10, a022608 (2018).

124. Korolev, A. V, Buschmann, H., Doonan, J. H. \& Lloyd, C. W. AtMAP70-5, a divergent member of the MAP70 family of microtubule-associated proteins, is required for anisotropic cell growth in Arabidopsis. J. Cell Sci. 120, 2241-2247 (2007).

125. Pesquet, E., Korolev, A. V, Calder, G. \& Lloyd, C. W. The microtubule-associated protein AtMAP70-5 regulates secondary wall patterning in Arabidopsis wood cells. Curr. Biol. 20, 744-749 (2010).

126. Lurin, C. et al. Genome-wide analysis of Arabidopsis pentatricopeptide repeat proteins reveals their essential role in organelle biogenesis. Plant Cell 16, 2089-2103 (2004).

127. Schmitz-Linneweber, C. \& Small, I. Pentatricopeptide repeat proteins: a socket set for organelle gene expression. Trends Plant Sci. 13, 663-670 (2008).

128. Kazama, T. \& Toriyama, K. A pentatricopeptide repeat-containing gene that promotes the processing of aberrant atp6 RNA of cytoplasmic male-sterile rice. FEBS Lett. 544, 99-102 (2003).

129. Laluk, K., AbuQamar, S. \& Mengiste, T. The Arabidopsis mitochondrial localized pentatricopeptide repeat protein PGN functions in defense against necrotrophic fungi and abiotic stress tolerance. Plant Physiol. pp--111 (2011).

130. Sharma, M. \& Pandey, G. K. Expansion and function of repeat domain proteins during stress and development in plants. Front. Plant Sci. 6, 1218 (2016).

131. Ohi, M. D., Vander Kooi, C. W., Rosenberg, J. A., Chazin, W. J. \& Gould, K. L. Structural insights into the U-box, a domain associated with multi-ubiquitination. Nat. Struct. Mol. Biol. 10, 250 (2003).

132. Zeng, L.-R., Park, C. H., Venu, R. C., Gough, J. \& Wang, G.-L. Classification, expression 
pattern, and E3 ligase activity assay of rice U-box-containing proteins. Mol. Plant 1, 800815 (2008).

133. Yee, D. \& Goring, D. R. The diversity of plant U-box E3 ubiquitin ligases: from upstream activators to downstream target substrates. J. Exp. Bot. 60, 1109-1121 (2009).

134. Samuel, M. A. et al. Interactions between the S-domain receptor kinases and AtPUBARM E3 ubiquitin ligases suggest a conserved signaling pathway in Arabidopsis. Plant Physiol. 147, 2084-2095 (2008).

135. Yao, Y., Xiao, X., Ou, Y., Wu, X. \& Xu, G. Root transcriptome analysis on the grape genotypes with contrast translocation pattern of excess manganese from root to shoot. Plant Soil 387, 49-67 (2015).

136. Dukanovic, J., Dimmer, K. S., Bonnefoy, N., Krumpe, K. \& Rapaport, D. Genetic and functional interactions between the mitochondrial outer membrane proteins Tom6 and Sam37. Mol. Cell. Biol. 29, 5975-5988 (2009).

137. Sakaki, K., Tashiro, K., Kuhara, S. \& Mihara, K. Response of genes associated with mitochondrial function to mild heat stress in yeast Saccharomyces cerevisiae. J. Biochem. 134, 373-384 (2003).

138. Serrano, I., Campos, L. \& Rivas, S. Roles of E3 ubiquitin-ligases in nuclear protein homeostasis during plant stress responses. Front. Plant Sci. 9, 139 (2018).

139. Shu, K. \& Yang, W. E3 ubiquitin ligases: Ubiquitous actors in plant development and abiotic stress responses. Plant Cell Physiol. 58, 1461-1476 (2017).

140. Lyzenga, W. J., Booth, J. K. \& Stone, S. L. The Arabidopsis RING-type E3 ligase XBAT32 mediates the proteasomal degradation of the ethylene biosynthetic enzyme, 1aminocyclopropane-1-carboxylate synthase 7. Plant J. 71, 23-34 (2012).

141. Stone, S. L. The role of ubiquitin and the $26 \mathrm{~S}$ proteasome in plant abiotic stress signaling. Front. Plant Sci. 5, 135 (2014).

142. Marinova, K. et al. The Arabidopsis MATE transporter TT12 acts as a vacuolar flavonoid/H+-antiporter active in proanthocyanidin-accumulating cells of the seed coat. Plant Cell 19, 2023-2038 (2007).

143. Chai, Y.-R. et al. TRANSPARENT TESTA 12 genes from Brassica napus and parental species: cloning, evolution, and differential involvement in yellow seed trait. Mol. Genet. Genomics 281, 109-123 (2009).

144. Wahid, A. \& Ghazanfar, A. Possible involvement of some secondary metabolites in salt tolerance of sugarcane. J. Plant Physiol. 163, 723-730 (2006). 
145. Hajrah, N. H. et al. Transcriptomic analysis of salt stress responsive genes in Rhazya stricta. PLoS One 12, e0177589 (2017).

146. Debeaujon, I., Peeters, A. J. M., Léon-Kloosterziel, K. M. \& Koornneef, M. The TRANSPARENT TESTA12 gene of Arabidopsis encodes a multidrug secondary transporter-like protein required for flavonoid sequestration in vacuoles of the seed coat endothelium. Plant Cell 13, 853-871 (2001).

147. Gong, Z. et al. ROS1, a repressor of transcriptional gene silencing in Arabidopsis, encodes a DNA glycosylase/lyase. Cell 111, 803-814 (2002).

148. Confalonieri, M. et al. Enhanced osmotic stress tolerance in Medicago truncatula plants overexpressing the DNA repair gene MtTdp2\$ $\alpha$ (tyrosyl-DNA phosphodiesterase 2). Plant Cell, Tissue Organ Cult. 116, 187-203 (2014).

149. Barbado, C., Córdoba-Cañero, D., Ariza, R. R. \& Roldán-Arjona, T. Nonenzymatic release of N7-methylguanine channels repair of abasic sites into an AP endonucleaseindependent pathway in Arabidopsis. Proc. Natl. Acad. Sci. 201719497 (2018).

150. Agius, F., Kapoor, A. \& Zhu, J.-K. Role of the Arabidopsis DNA glycosylase/lyase ROS1 in active DNA demethylation. Proc. Natl. Acad. Sci. 103, 11796-11801 (2006).

151. Li, Y. et al. An AP endonuclease functions in active DNA demethylation and gene imprinting in Arabidopsis. PLoS Genet. 11, e1004905 (2015).

152. Pasrija, R. \& Thakur, J. K. Analysis of differential expression of Mediator subunit genes in Arabidopsis. Plant Signal. Behav. 7, 1676-1686 (2012).

153. Autran, D. et al. Cell numbers and leaf development in Arabidopsis: a functional analysis of the STRUWWELPETER gene. EMBO J. 21, 6036-6049 (2002).

154. Ito, J., Sono, T., Tasaka, M. \& Furutani, M. MACCHI-BOU 2 is required for early embryo patterning and cotyledon organogenesis in Arabidopsis. Plant cell Physiol. 52, 539-552 (2011).

155. Elfving, N. et al. The Arabidopsis thaliana Med25 mediator subunit integrates environmental cues to control plant development. Proc. Natl. Acad. Sci. 108, 8245-8250 (2011).

156. Kidd, B. N. et al. The mediator complex subunit PFT1 is a key regulator of jasmonatedependent defense in Arabidopsis. Plant Cell 21, 2237-2252 (2009).

157. Oka, M., Maruyama, J., Arioka, M., Nakajima, H. \& Kitamoto, K. Molecular cloning and functional characterization of avaB, a gene encoding Vam6p/Vps39p-like protein in Aspergillus nidulans. FEMS Microbiol. Lett. 232, 113-121 (2004). 
158. Pandey, V., Singh, M., Pandey, D., Marla, S. \& Kumar, A. Secretome Analysis Identifies Potential Pathogenicity/Virulence Factors of Tilletia indica, a Quarantined Fungal Pathogen Inciting Karnal Bunt Disease in Wheat. Proteomics 18, 1700473 (2018).

159. Singh, K. B., Foley, R. C. \& Oñate-Sánchez, L. Transcription factors in plant defense and stress responses. Curr. Opin. Plant Biol. 5, 430-436 (2002).

160. Lakra, N. et al. A nuclear-localized histone-gene binding protein from rice (OsHBP1b) functions in salinity and drought stress tolerance by maintaining chlorophyll content and improving the antioxidant machinery. J. Plant Physiol. 176, 36-46 (2015).

161. Dettmer, J. et al. CHOLINE TRANSPORTER-LIKE1 is required for sieve plate development to mediate long-distance cell-to-cell communication. Nat. Commun. 5, 4276 (2014).

162. Shapira, O., Goldstein, A., Al-Bassam, J. \& Gheber, L. Possible physiological role for bidirectional motility and motor clustering of the mitotic kinesin-5 Cin8. J Cell Sci jcs-195040 (2017).

163. Reddy, A. S. N. \& Day, I. S. Kinesins in the Arabidopsis genome: a comparative analysis among eukaryotes. BMC Genomics 2, 2 (2001).

164. Ambrose, J. C. \& Cyr, R. The kinesin ATK5 functions in early spindle assembly in Arabidopsis. Plant Cell 19, 226-236 (2007).

165. Zhu, C. \& Dixit, R. Functions of the Arabidopsis kinesin superfamily of microtubulebased motor proteins. Protoplasma 249, 887-899 (2012).

166. Bannigan, A. et al. A conserved role for kinesin-5 in plant mitosis. J. Cell Sci. 120, 28192827 (2007).

167. Baloch, F. S. et al. A whole genome DArTseq and SNP analysis for genetic diversity assessment in durum wheat from central fertile crescent. PLoS One 12, e0167821 (2017).

168. Neumann, K., Kobiljski, B., Denčić, S., Varshney, R. K. \& Börner, a. Genome-wide association mapping: a case study in bread wheat (Triticum aestivum L.). Mol. Breed. 27, 37-58 (2010).

169. Gujaria, N. et al. Development and use of genic molecular markers (GMMs) for construction of a transcript map of chickpea (Cicer arietinum L.). Theor. Appl. Genet. 122, 1577-1589 (2011).

170. Jaganathan, D. et al. Genotyping-by-sequencing based intra-specific genetic map refines a "QTL-hotspot” region for drought tolerance in chickpea. Mol. Genet. Genomics 290, 559-571 (2015). 
171. Thudi, M. et al. Novel SSR markers from BAC-end sequences, DArT arrays and a comprehensive genetic map with 1,291 marker loci for chickpea (Cicer arietinum L.). PLoS One 6, e27275 (2011).

172. Kale, S. M. et al. Prioritization of candidate genes in "QTL-hotspot" region for drought tolerance in chickpea (Cicer arietinum L.). Sci. Rep. 5, 15296 (2015).

173. Rehman, A. U. Characterization and molecular mapping of drought tolerance in kabuli chickpea (Cicer arietinum L.). (University of Saskatchewan, 2009).

174. Gowda, S. J. M. et al. Mapping of QTLs governing agronomic and yield traits in chickpea. J. Appl. Genet. 52, 9-21 (2011).

175. Samineni, S. Physiology, genetics and QTL mapping of salt tolerance in chickpea (Cicer arietinum L.). (University of Western Australia, 2010).

176. Varshney, R. K. et al. Genetic dissection of drought tolerance in chickpea (Cicer arietinum L.). Theor. Appl. Genet. 127, 445-462 (2014).

177. Nayak, S. N. Identification of QTLs and genes for drought tolerance using linkage mapping and association mapping approaches in chickpea (Cicer arietinum). (Osmania University, Hyderabad, India, 2010).

178. Hamwieh, A., Imtiaz, M. \& Malhotra, R. S. Multi-environment QTL analyses for droughtrelated traits in a recombinant inbred population of chickpea (Cicer arientinum L.). Theor. Appl. Genet. 126, 1025-1038 (2013).

179. Hiremath, P. J. et al. Large-scale development of cost-effective SNP marker assays for diversity assessment and genetic mapping in chickpea and comparative mapping in legumes. Plant Biotechnol. J. 10, 716-732 (2012).

180. Pushpavalli, R. et al. Two key genomic regions harbour QTLs for salinity tolerance in ICCV $2 \times$ JG 11 derived chickpea ( Cicer arietinum L .) recombinant inbred lines. ??? 115 (2015). doi:10.1186/s12870-015-0491-8. 